\title{
NORFACE
}

MIGRATION

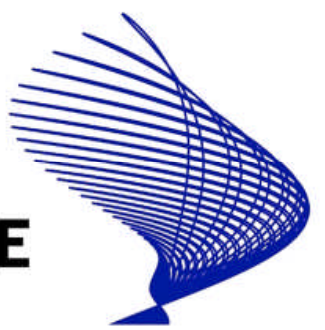

NORFACE MIGRATION Discussion Paper No. 2013-20

\section{Directed Giving: Evidence from an Inter-Household Transfer Experiment}

Catia Batista, Dan Silverman and Dean Yang 


\title{
Directed Giving: Evidence from an Inter-Household Transfer Experiment ${ }^{*}$
}

\author{
Catia Batista, Nova University of Lisbon and IZA \\ Dan Silverman, Arizona State University and NBER \\ Dean Yang, University of Michigan, NBER, and BREAD
}

July 2013

\begin{abstract}
We investigate the determinants of giving in a lab-in-the-field experiment with large stakes. Study participants in urban Mozambique play dictator games where their counterpart is the closest person to them outside their household. Dictators share more with counterparts when they have the option of giving in kind (in the form of goods), compared to giving that must be in cash. Qualitative post-experiment responses suggest that this effect is driven by a desire to control how recipients use gifted resources. Standard economic determinants such as the rate of return to giving and the size of the endowment also affect giving, but the effects of even large changes in these determinants are significantly smaller than the effect of the in-kind option. Our results support theories of giving where the utility of givers depends on the composition (not just the level) of gift-recipient expenditures, and givers thus seek control over transferred resources.
\end{abstract}

Keywords: sharing, altruism, giving, dictator game, inter-household transfers, Mozambique JEL Codes: C92, C93, D01, D03, D64, O17

\footnotetext{
* Batista: Faculdade de Economia, Universidade Nova de Lisboa and IZA (catia.batista@novasbe.pt); Silverman: Department of Economics, Arizona State University and NBER (Daniel.Silverman.1@asu.edu); Yang (corresponding author): Department of Economics and Gerald R. Ford School of Public Policy, University of Michigan, NBER, and BREAD (deanyang@umich.edu). We appreciate comments and suggestions of seminar participants at the University of Michigan and Stanford University. Cheney Wells, our IPA Project Associate, deserves special thanks for superb work on all aspects of project implementation and data management. This project would not have been possible without the collaboration of Banco Oportunidade de Mocambique (BOM); we greatly appreciate the support of Kathryn Larcombe and Douglas Pond at BOM. This study was funded by the International Growth Centre (IGC) and the Agricultural Technology Adoption Initiative (ATAI).
} 


\section{Introduction}

In both rich and poor countries, transfers of resources across individuals and across households are common and often large in magnitude. In developing countries, inter-household transfers play an important role in replacing public transfers when those public sources are not available (Cox and Jimenez, 1992; Cox et al. 2004; Jensen 2004; Kazianga 2006). Similarly, informal transfer and credit relationships between households also augment missing insurance markets in developing countries (Townsend 1994, Udry 1994, Jalan and Ravallion 1999, Angelucci et al 2010). In developed countries, inter-household transfers are also widespread (Altonji et al 1992, 1997; Bernheim et al 2004; Arrondel and Masson 2006).

Becker's (1974) model of altruistic transfers is the seminal theory of intra-household transfers. This model was subject to an early test by Cox (1987), who found that inter vivos transfers were more consistent with exchange-related motives than with pure altruism. A recent literature has used experimental methods to examine motivations behind giving. Studies have explored the existence and nature of altruistic motives for giving, such as Andreoni and Vesterlund (2001), Andreoni and Miller (2002), Camerer and Fehr (2004), and DellaVigna et al (2012). Other work, such as Leider et al (2009) and Ligon and Schechter (2010), has highlighted that transfers may reflect selfish or "exchange” motives - desires on the part of givers to reward recipients for past behavior or to influence future behavior - in addition to altruism. ${ }^{1}$

In this paper, we examine a cross-cutting issue: whether and how givers seek to influence or control the consumption patterns of gift recipients. Would an ability to wield control over recipient consumption out of gifted resources affect givers' expected utility from giving, and their giving decisions overall?

To our knowledge, this question - whether and how givers value "directed” giving - has not been addressed in the literature, and it has potentially important theoretical and practical implications. From a theoretical standpoint, evidence of a desire for control on the part of givers rules out certain models of the giving decision - for example, it is inconsistent with a simple model of pure altruism and perfect rationality on the part of givers and recipients.

Evidence on directed giving motives could also have important practical or policy implications. If such motives exist and play a quantitatively substantial role, real-world transfer

\footnotetext{
${ }^{1}$ Barr and Genicot (2008) and Attanasio et al (2012) use experiments to examine the determinants of the composition and functioning of informal risk-sharing networks.
} 
behavior may be affected by regulatory or technological developments that facilitate givers' control over recipient consumption. For example, new technologies such as the Internet facilitate in-kind giving over distances (via online merchants), and telecommunications can improve longdistance monitoring of transfer recipients. In the legal realm, trusts and other legal instruments allow givers to place limits on how recipients can use inter-vivos transfers and bequests. In the charitable giving context, directed giving motives might explain the strategy of soliciting donations for specific, defined uses, rather than general ones. Directed giving motives could also explain political support for government programs providing government transfers in kind (e.g., the US SNAP or "Food Stamps" program) instead of in cash.

The question we pose is also related to research on the motivations behind in-kind giving. Giving often takes the form of cash transfers, but a substantial share of giving is in-kind, meaning it is in the form of non-cash goods and services. Standard models of giving imply that gift-givers, who may not be fully aware of recipient preferences, cannot do better at raising recipient utility than by giving cash (as opposed to making in-kind gifts), which can then allow recipients to make utility-maximizing consumption choices on their own. ${ }^{2}$ The prevalence of inkind giving is therefore a puzzle.

Alternative hypotheses have been proposed to explain this puzzle. Pollak (1988) presents inkind gifts, or tied transfers, within the family as direct consequences of paternalistic preferences, where parents derive utility from their children's consumption of only a subset of goods from their children's overall consumption basket. In-kind gifts are just a way to promote the consumption of those preferred goods. Waldfogel (1993) hypothesizes that individuals may give in-kind gifts if they think they know the recipient's preferences better than recipients do themselves. His data reject this hypothesis, however: undergraduates report valuing in-kind gifts received at large discounts relative to market prices. Prendergast and Stole (2001) instead rationalize in-kind gifts in a signaling model. They hypothesize that in-kind gifts allow givers to send positive signals to recipients, by putting in the effort to select a gift and to show the recipient that the giver knows the recipient’s preferences well. Our "directed giving” hypothesis provides an alternative explanation for in-kind giving.

\footnotetext{
${ }^{2}$ An exception would occur when an altruistic gift-giver is faced with the "Samaritan's dilemma," i.e. when the recipient's optimal dynamic strategy is to over-spend in early periods in the expectation that the giver will increase the value of gifts at later periods if the recipient's income is low at that time. In this setting, in-kind gifts in early periods would be a way to rein in over-spending by the recipient, which would likely be welfare-enhancing. This argument is formalized by Bruce and Waldman (1991).
} 
A number of theoretical approaches can generate directed giving, or giving in which givers seek control over the use of transferred resources. In the examples we discuss, givers' desire for control arises because giver utility depends on the composition (not just the level) of giftrecipient expenditures. For example, in a paternalistic model, givers may value the utility recipients gain from consumption of "virtue” goods, but not recipient utility from consumption of "vice” goods. This makes it possible for givers to raise their own utility from giving by making in-kind gifts. An alternative model is one where gift recipients may consume either "public" goods (goods which generate utility for givers as well as recipients) or "private” goods (which generate utility only for recipients). ${ }^{3}$ In this public goods model, givers can raise their own utility from giving by making in-kind gifts of public goods. In both the paternalistic and public goods models, giver utility rises with in-kind giving because givers can control recipient consumption patterns better with in-kind gifts than with cash gifts. Both models make ambiguous predictions as to whether the possibility of making in-kind gifts leads to more or less gift-giving overall.

The main contribution of our paper is to provide the first direct experimental evidence supporting a class of models that generate motives for directed giving. In addition, we reveal a pattern in the results that is distinctive of the paternalistic model and thus suggests this model more relevant than either the public goods or the signaling model of giving. We conduct a lab-inthe-field experiment with large stakes. Respondents were clients of a microfinance institution in urban Mozambique, and played a series of dictator games in which their counterpart (the recipient of gifted funds) was, according to the respondents, the closest person to them outside of their own household. One of the choices made by each respondent is, at the end of the experiment, chosen at random to be implemented in reality. ${ }^{4}$

Our focus on transfers between members of a social network distinguishes our research from the vast majority of dictator game experiments on willingness to give anonymously to unknown recipients with whom no future interaction is expected. Leider et al (2009) and Ligon and Schechter (2010) are recent exceptions that also study individuals with social ties. In our view,

\footnotetext{
${ }^{3}$ Examples of public goods in this context include housing and other household durables, which may be enjoyed by givers on occasion, or investments in children in the recipient household who are related to the giver.

${ }^{4}$ A key advantage of the Mozambique sample is that income levels are relatively low by developed-country standards, allowing us to implement a high-stakes experiment (from the respondent standpoint) on a reasonable research budget. The value of the endowment allocated by respondents ranged across experimental choices from 4 to $16 \%$ of median monthly household consumption in the sample.
} 
experiments on non-anonymous giving in social networks merit greater attention. Many have observed that the level of sharing in anonymous lab settings is high relative to similar interactions of strangers outside the lab (e.g., Della Vigna, 2009). This suggests that the motives behind giving in classic dictator game experiments may be different from those that inspire the large amounts of giving that occurs between members of social networks. Our experiment is designed to understand better the motives for giving among friends and family.

By studying giving within a social network, we lose an advantage of anonymous giving experiments. Because we expect our subjects to interact after the experiment, the possibility that they are playing a repeated game makes interpretation of their behavior in the experiment more difficult. To aid interpretation, we will use our experimental results and a survey of the participants to investigate the role played by repeated interaction. In particular, we will look for evidence of favor trading after the experiment and for evidence that givers favored durable goods that could serve as tangible reminders of their favor to recipients. We will also look for evidence of standard economic advantages of giving in-kind rather than cash, such as convenience or price, that would motivate in-kind giving in repeated games among agents with standard preferences. This is important because, as explained below, the advantages of cash giving in static models also apply to many dynamic ones.

We find that in-kind giving amounts to a substantial share of giving. When respondents can freely choose to give in cash or in kind, they give $25.9 \%$ of the endowment in cash and $19.2 \%$ in kind; in-kind giving therefore accounts for $42.6 \%$ of giving. ${ }^{5}$

Another key finding is that offering respondents the option of in-kind giving leads to substantially more total giving. When gifts can only be made in cash, respondents give away $39.6 \%$ of their endowments. But when respondents also have the option of making in-kind gifts (in addition to cash gifts), they give $45.1 \%$ of their endowments. This 5.5 percentage point increase amounts to about three-tenths of a standard deviation of the percentage given in the experiment.

The in-kind effect is also large relative to the effect of other determinants of giving in our experiment. A very large increase in the rate of return to giving (moving from $0 \%$ to $200 \%$

\footnotetext{
${ }^{5}$ The in-kind giving choices in this and the following paragraph refer to experimental rounds 5-8, the "in kind with respondent purchase” rounds. See Section 3 and the Appendix for further details.
} 
return) raises the fraction shared by 2.4 percentage points, ${ }^{6}$ while a four-fold increase in the size of the endowment given to respondents (from 300 to 1200 meticais) leads sharing to fall by 2.7 percentage points. ${ }^{7}$ The in-kind effect is therefore at least twice as large in magnitude as the effects of these very large changes in other economic determinants of giving.

These results are consistent with both directed giving models (paternalistic and public goods models), as well as a signaling model of giving (Prendergast and Stole 2001) where givers seek to demonstrate how well they know the preferences of their recipients. To distinguish among these models, we implemented additional experimental choices where givers could not make the exact in-kind consumption choices themselves. In these rounds, givers only specified the money amounts allocated to in-kind goods, and recipients made the final choice of goods purchased with these in-kind funds. ${ }^{8}$ The goods that recipients could choose among in these in-kind allocations included both public and private goods; in other words, givers could not control whether recipients chose public vs. private goods. The manner of selection of the in-kind goods by gift recipients was such that recipients could not use the in-kind resources for expenditures such as alcohol, tobacco, or entertainment, that would be viewed by givers as unproductive or inappropriate (vice goods). Making in-kind gifts in this fashion would also presumably have no signaling value. If in-kind giving is little affected by the ability to ensure the gift takes the form of public goods, then paternalism, rather than public good consumption or signaling, is the dominant motive behind in-kind giving.

We find that offering this form of the in-kind option also has a statistically significant positive effect on giving. This effect is only slightly smaller than the effect of the main in-kind option (where respondents make final purchase decisions), and the two in-kind effects are statistically indistinguishable from one another. The fact that the in-kind effect is still positive and significant when recipients make final purchase decisions suggests that the paternalistic model of giving is the most empirically relevant in this context.

Additional analysis helps us evaluate other explanations for the results. We provide evidence - based on an examination of heterogeneity in the treatment effect - against the hypotheses that

\footnotetext{
${ }^{6}$ In experimental rounds with a rate of return to giving of $\mathrm{x} \%$, each amount a respondent gave out of their endowment to the counterpart was “matched” by the experiment with funds amounting to an additional $\mathrm{x} \%$ and then shared with the counterpart.

${ }^{7}$ One US dollar was worth roughly 27 Mozambican meticais during the time period of this experiment.

8 This is analogous to "gift cards" that are common in more developed economies, which provide funds that are to be used in specific establishments (stores, restaurants, etc.) but cannot be directly converted to cash.
} 
the "in-kind effect" reflects the value of free delivery of the in-kind items, the opportunity for counterparts to consume goods not available in their local areas, or the opportunity to give the counterpart a tangible reminder of the giver's generosity.

As a final test of whether the in-kind effect is driven by directed giving as opposed to other motivations, we examine qualitative respondent self-reports on their own motivations for in-kind giving. These data reveal that a desire to control how recipients use gifted resources figures

prominently in decisions to give in kind, and these individual-level responses correlate positively with the extent to which respondents increase their own giving in response to the in-kind option in the experiment. Other motivations for in-kind giving figure much less prominently in these qualitative data.

The remainder of the paper is organized as follows. Section 2 presents a model of directed giving. Section 3 describes the experiment and the baseline data. Section 4 presents the main empirical results, quantifying the in-kind effect. Section 5 presents additional empirical analyses intended to reveal the mechanisms behind the in-kind effect. Section 6 concludes.

\section{Directed Giving in Theory}

We present here two simple models that generate directed giving, or giving in which givers seek control over the use of transferred resources: a paternalistic model and a public goods model. In both cases, givers' desire for control arises because giver utility depends on the composition, not just the level, of gift-recipient expenditures. Giver utility therefore rises with inkind giving because givers can control recipient consumption patterns better with in-kind gifts than with cash. Both models make ambiguous predictions as to whether the possibility of making in-kind gifts leads to more or less gift-giving overall.

\section{A paternalistic model of giving}

In this model, givers value the utility recipients gain from consumption of so-called "virtue" goods, but not recipient utility from consumption of "vice” goods. This makes it possible for givers to raise their own utility from giving by making in-kind gifts.

An altruistic "giver" decides how much of a windfall to donate to a recipient, either in cash or in kind. Suppose, for simplicity, that there are two composite goods $x$ and $y$ with prices $p_{x}$ and $p_{y}$ denominated in meticais. To make the discussion more vivid, we will call $x$ the virtue 
good, and $y$ the vice good.

In the absence of a gift, a recipient with wealth $\omega$ would solve

$$
\begin{array}{ll} 
& \max _{x, y} u(x)+v(y) \\
\text { s.t. } & \omega-p_{x} x-p_{y} y \geq 0 \\
& x, y \geq 0
\end{array}
$$

Under standard assumptions, the recipient's indirect utility is a well-behaved function of wealth, $R(\omega)$; so if the giver donates some amount of cash $g$ to the recipient then the benefit to the recipient is $R(\omega+g)-R(\omega)$. Denote by $x^{*}(g), y^{*}(g)$ the optimal choices associated with a cash gift of size $g$.

Suppose instead that the giver allocates an amount $k$ of the virtue good to the recipient. Assume that this gift cannot be sold for cash but that its market value is $g \quad\left(p_{x} k=g\right)$. In this case, the recipient solves

$$
\begin{array}{ll} 
& \max _{x, y} u(x+k)+v(y) \\
\text { s.t. } & \omega-p_{x} x-p_{y} y \geq 0 \\
& x, y \geq 0
\end{array}
$$

If the solution to this problem is interior, then the recipient's optimal choices $\tilde{x}, \quad \tilde{y}$ satisfy $\frac{u^{\prime}(\tilde{x}+k)}{v^{\prime}(\tilde{y})}=\frac{p_{x}}{p_{y}}, \quad \tilde{x}+k=x^{*}(g)$, and $\tilde{y}=y^{*}(g)$. In other words, the giver's demand that the recipient consume at least $k$ of the virtue good is not binding in this case; and the recipient's ultimate consumption (utility) does not depend on whether the gift with a market value of $g$ meticais was cash or in-kind.

In the more interesting case, the size of the in-kind gift, $k$, exceeds the amount of the virtue good that the recipient would have chosen were the gift to be made in cash, $x^{*}(g)$. A standard argument about the advantages of cash over in-kind assistance then applies. If $k>x^{*}(g)$ the recipient is worse off than she would be with the gift's cash equivalent, $g$. We know this is true because the allocation $(x, y)=(k, \tilde{y})$ is feasible when the recipient is allocated the cash gift $g$, 
but she does not choose it. By revealed preference, the insistence that she consume at least $k$ of the virtue good is therefore worse for the recipient.

This is not to say that the in-kind gift harms the recipient. So long as she values the virtue good at the margin, the recipient benefits from the in-kind gift, even if it is "oversized." We will denote by $K(\omega, k)$ the indirect utility of the recipient with wealth $\omega$ and who has been allocated an in-kind gift of size $k$. Using this notation, the standard argument about the advantages of cash assistance given above then implies that for a gift composed of a cash amount $i$ and an in-kind amount $k$, such that, $p_{x} k+i=g$,

$$
R(\omega+g) \geq K(\omega+i, k)
$$

and the inequality is strict if $k>x^{*}(g)$.

The argument behind inequality (1) makes in-kind giving a puzzle for simple models of altruism. We offer here a simple theory of in-kind gifts. The theory is a blend of altruism and paternalism. In a standard model of altruism, when given a money windfall of size $m$ the giver solves

$$
\begin{array}{ll} 
& \max _{c, i, k}(1-\alpha) V(c)+\alpha K(\omega+i, k) \\
\text { s.t. } & m-c+\frac{\left(i-p_{x} k\right)}{1+r} \geq 0 \\
& c, i, k \geq 0
\end{array}
$$

where $V(c)$ is the giver's utility from consumption of a composite good $c$ denominated in meticais, $\alpha \in[0,1]$ gives the altruistic weight on the recipient's utility, and all other variables are defined as above. Anticipating our experiments, we also introduce a relative price of giving $r$. When $r$ is higher, giving is cheaper. Inequality (1) from above implies that giving nothing in kind, $k^{*}=0$, solves this altruistic giver's problem. If, in addition, we set aside cases where the giver is just indifferent between cash and in-kind because the in-kind gift would not bind, then in-kind giving is never optimal.

Suppose, instead, that the giver, while altruistic, does not entirely respect the preferences of the recipient. He cares about her well-being only along certain dimensions. For simplicity, 
assume that the giver respects only the recipient's consumption of virtue goods. In this case, the giver solves

$$
\begin{array}{ll} 
& \max _{c, i, k}(1-\alpha) V(c)+\alpha \tilde{u}(i, k) \\
\text { s.t. } & m-c-\frac{\left(i+p_{x} k\right)}{1+r} \geq 0 \\
& c, i, k \geq 0
\end{array}
$$

where $\widetilde{u}(i, k)$ gives the value from virtue good consumption of a recipient who received a gift consisting of cash $i$ and in-kind amount $k$. That is,

$$
\widetilde{u}(i, k) \equiv u\left(x^{*}(\omega+i, k)\right)
$$

where $x^{*}(\omega+i, k)$ solves problem (P) above given wealth $\omega+i$ and in-kind gift $k$.

This simple model of altruism tinged by paternalism makes sense of in-kind gifts. More precisely, this model implies:

Result 1: The giver strictly prefers an in-kind gift $k$ with market value $g$ to a cash gift of $g$ if and only if $k>x^{*}(g)$.

In other words, the giver prefers to give in-kind whenever it generates more consumption of the virtue good than would occur if he just gave cash. That is true because, in this simple model, the giver places zero value on the recipient's vice good consumption and values her virtue good consumption monotonically. Note that, if we set aside knife-edge cases of indifference, this simple model also predicts that gifts would never combine of cash and in-kind. A richer model of giver preferences that, instead of entirely ignoring vice utility only gave it a weight less than one, would predict that some gifts would consist of both cash and in-kind. In these cases, the giver would equate the marginal altruistic utility from giving in-kind with the marginal altruistic utility from giving cash.

Result 2: The level of virtue good consumption is weakly higher when the option to give inkind is available.

Proof: See Appendix A. Let $\hat{g}$ denote the optimal gift when only cash can be given, and $\left(i^{\prime}, k^{\prime}\right)$ the optimal gift when both forms of giving are possible. If $\hat{g}=0$, the claim is trivially true. Suppose instead $\hat{g}>0$ and, contrary to the claim, $x^{*}\left(i^{\prime}, k^{\prime}\right)<x^{*}(\hat{g})$. The alternative 
allocation $\left(0, k^{\prime \prime}\right)$ where $k^{\prime \prime}=x^{*}(\hat{g})$ generates strictly higher utility from altruism than $\left(i^{\prime}, k^{\prime}\right)$. Most important, because the vice good is normal, the marginal propensity to consume the virtue good is less than one and therefore

$$
p_{x} k^{\prime \prime} \leq \hat{g}
$$

It follows that if the gift $\hat{g}$ was feasible then so is $\left(0, k^{\prime \prime}\right)$, and this alternative gift leaves the giver with at least as much own consumption as the strictly cash gift $\hat{g}$. By construction, marginal utility to the giver from altruism is the same at gift $\left(0, k^{\prime \prime}\right)$ as at $(\hat{g}, 0)$, and we have just argued that marginal utility from own consumption is weakly lower. Thus, either $\left(0, k^{\prime \prime}\right)$ is optimal, or an even larger in-kind gift is preferred.

Inequality (2) isolates the key effect on the giver of providing the in-kind option. The possibility of giving in-kind lowers the effective price, in terms of own consumption $c$, of producing virtue good consumption and thus altruistic utility. This effective price change generates income and substitution effects which both point in the same direction. The substitution effect gives incentive to buy more virtue good and less own consumption, and the income effect creates incentive to buy more of both.

If we understand that the introduction of the in-kind option effectively reduces the price to the giver of generating recipient virtue good consumption, it is straightforward to see that the net effect on the total market value of the gift, or its complement $c$, is ambiguous. The lower effective price of getting the recipient to consume the virtue good creates incentive for the giver to substitute out of own consumption and into giving (the substitution effect). But the lower effective price makes every level of virtue good production cheaper, in terms of $c$, to obtain, and thus creates incentive to purchase more own consumption (income effect). Whether the market value of the gift increases when the in-kind option becomes available depends, therefore, on the relative magnitude of these income and substitution effects.

Result 3: The introduction of the in-kind option has an ambiguous effect on the total market value of the gift.

A public goods model of giving 
A related but distinct model of directed giving is one where gift recipients may consume either "public" goods (goods which generate utility for givers as well as recipients) or "private" goods (which generate utility only for recipients). In this public goods model, givers can raise their own utility from giving by making in-kind gifts of public goods.

In the interest of brevity, we provide the formal exposition of this model in Appendix A, and simply note here that the model makes similar predictions to the paternalistic model. In particular, analogs of Results 1 through 3, discussed above in the context of the paternalistic model, also hold in the public goods model.

\section{Impure altruism and in-kind giving}

These two simple models of giving address the puzzle that in-kind giving presents for standard models of altruism. In a standard model of altruism, where all goods are private and the donor's utility simply includes a positive weight on the utility of their recipient, giving in-kind can never help, and might hurt.

This observation has motivated alternative models of giving that rationalize in-kind gifts. Waldfogel (1993) offers a model of altruistic donors, and recipients who may not know, with certainty, what consumption bundle they would prefer. The model thus opens the possibility that a donor may know his recipient better than she knows herself. At a minimum, it creates the incentive for a donor to take on a bit of risk by giving in-kind with the hope that the realization of the utility from the gift beats the safe return from giving cash. Prendergast and Stole (2001) take a different approach. They motivate non-monetary gifts with a donor's preference to be perceived as confident about what the receiver would like. By purchasing a gift, the donor issues a costly signal that he is so confident in the preferences of the recipient he is willing to give inkind rather than cash. That model explains both why people give non-monetary gifts, and why, when it comes to gifts, the thought alone does not count as much as the thought backed up by an actual purchase.

The two simple models presented above suggest alternative motivations for giving in kind. In the paternalistic model, the donor simply gains utility from the recipient's consumption of some goods (virtue goods), but not others (vice goods). In the public goods model, the mechanism behind in-kind giving is shared consumption. In many settings, both donor and recipient may gain utility from a gift, not because the donor is altruistic, but because the donor, in effect, 
consumes the gift as well.

These are different forms of impure altruism than the one developed in Andreoni (1989, 1990). In Andreoni's models, the donor is motivated to by the warm glow he derives from the gift. This impure altruism doesn't induce preferences over in-kind vs. cash giving. In our models, the donor's altruism is again impure but structured in particular ways. The common feature of the models we present is that the donor's utility is influenced by the composition of recipient expenditures (even when the level of recipient expenditures is held constant). The donor gives in kind, and thus benefits the recipient, because she either induces consumption of the particular (“virtue”) goods she differentially values, or procures valuable public goods for herself.

\section{Distinguishing among the models}

While the paternalistic and the public goods model share many predictions, a test allows us to distinguish between them and, as a byproduct, shed light on the relevance of the signaling model. The test examines whether givers still seek in-kind giving if the in-kind allocations can only be made to a very broad set of goods that includes a mixture of public and private goods, but that excludes “vice” goods. To be specific (and anticipating our experimental setup), consider a situation where in-kind giving involves providing recipients with something akin to a gift card, that can be used for purchases of a wide range of goods from a catalog, but that rules out use for vices (e.g., alcohol, tobacco, or sex services).

In such a scenario, paternalistic givers would value in-kind giving just as much as they did when they directly controlled the purchases, so long as vice goods are not in the catalog. Because the catalog includes both private and public goods, however, givers motivated by their interest in consuming public goods will value this form of giving much less than when they directly controlled the purchases. The value to the giver of an in-kind gift is diminished, in this scenario, by the recipients' purchases of private goods. ${ }^{9}$ In addition, there would also be no value of inkind giving under the signaling model, as givers would be unable to signal their knowledge of recipient preferences.

\footnotetext{
${ }^{9}$ The value of the in-kind option without direct control does not go to zero so long as, by constraining the recipient to choose from the catalog, the giver induces more public good consumption than she would by giving a cash amount of equal value.
} 
Result 4: If givers assign the same value to direct control of an in-kind option as to an inkind option that excludes only vice goods, this would be consistent with a paternalistic model, but not with either a public goods or signaling model of giving.

This result motivates our first analysis in Section 5 below.

\section{Background, Sample, and Description of Intervention}

Sample and baseline survey

Participants were individuals with savings accounts at Banco Opportunidade de Moçambique (BOM), our local project partner. BOM is a microfinance bank in the Opportunity International network. It has two branches in the Maputo capital city area at which we conducted this study. Participants were interviewed immediately before the experiment between May and July 2012, along with their counterparts. ${ }^{10}$

The interviewer team had a desk at each of the two Maputo branches of BOM and invited savings account holders visiting the branch when the team was present to participate in the experiment. ${ }^{11}$ To be considered eligible, a respondent had to identify a counterpart at their "most closely connected household" (MCCH) outside of their own home who owned a cell phone and had a bank account (other than one shared with the respondent). This selection criterion was designed to allow for phone interviews of the counterpart and bank transfers of the monetary payoffs from the experiment. ${ }^{12}$

The baseline survey was administered immediately before the experiment and asked questions about the participants' demographic characteristics, labor market status, expenditure patterns and property ownership, as well as on gift giving (and receiving) behavior.

\footnotetext{
${ }^{10}$ A simultaneous 10-minute phone interview was conducted with the counterpart of each participant. At the beginning of the phone interview, clients were asked to briefly talk to their counterpart, reassuring them that they were collaborating with the research team conducting the interviews and summarizing the purpose of the project. It was not possible to contact 29 counterparts (or 12.1\%) of the clients interviewed. A few counterpart interviews (6.9\%) were not conducted at the same time as client interviews, but sometime within the week following the initial client interview.

${ }^{11}$ Interviewer teams were present in the BOM branches during all working hours of all working days. For project funding reasons, there were two spells of interviewer presence at BOM branches: the first started on May $2^{\text {nd }}$ and ended on May $17^{\text {th }}$; the second went from June $18^{\text {th }}$ to July $20^{\text {th }}$.

${ }^{12}$ Of a total of 283 individuals approached and willing to participate in the survey during the two fieldwork spells described above, 26 individuals (9.2\%) could not be interviewed because their counterpart in the MCCH did not have access to a bank account and 13 individuals (4.6\%) were excluded because their counterpart did not own a cell phone.
} 
Our sample of interest consists of 239 respondents who were administered the baseline survey and asked to make the dictator-game allocations. We excluded a small number (5) of individuals who did not provide complete responses to all experimental rounds.

Table 1 presents summary statistics from the baseline survey. Nearly half of the sampled respondents (47 percent) were females. Respondents had a median age of 34 years and 57 percent of these respondents had not been born in Maputo city. A majority (61 percent) were or had been married before, and the median household size was 5 people. A large fraction (80 percent) of the respondents in our sample had completed primary school and 27 percent had finished high school. Most (77 percent) of the respondents in our sample reported being employed. Median monthly household expenditure was 7,425 meticais (roughly US\$275), 74 percent of the respondents reported owning their home, 48 owned agricultural land, 41 owned farm animals, and 27 percent owned a car.

We note that 21 percent of the counterparts to our respondents do not live in the greater Maputo city area, i.e. their closest relationship outside the home is in a distant location. In terms of transfers made, 60 percent of the respondents in the baseline sample report having given cash to their counterparts over the past year. The average of annual cash transfers is 5,668 meticais. Many (46 percent) report having made in-kind transfers to their counterparts over the past year. Annual in-kind transfers are valued at an average of 687 meticais. Overall, 66 percent of the individuals in our sample state they have given money or goods to their counterpart in the MCCH, and average annual transfers are valued at 6,355 meticais.

Table 1 also presents data on transfers received by the participants in the experiment from their counterparts in the MCCH, which are also substantial. More than half (56 percent) of the baseline survey respondents report having received cash from their counterparts in the MCCH (with an annual average value of 2,995), whereas 51 percent declare having received in-kind gifts (with an average value of 1,453 meticais). In total, 66 percent of the respondents in the baseline survey received either money or gifts from their counterparts in the MCCH, with an average annual value of 4,448 meticais. The percentage of people sending remittances is therefore very close to the percentage of people receiving transfers, although the annual amount of cash received is only about $70 \%$ of the annual amount sent.

Table 2 shows the relationship between the respondents in the baseline sample and their counterparts in the MCCH outside of their home. There is some diversity, but these counterparts 
tend to be siblings (nearly one third), followed by friends (about 17 percent), cousins and children (each around 10 percent).

\section{Description of experiment}

The experimental intervention was administered to participants face-to-face, immediately after they answered the baseline survey and their counterparts simultaneously answered their survey over the phone.

The intervention consisted of proposing a number of choices to participants, so that they could decide on the allocation of a large real stake that could be as high as 3600 meticais (roughly US\$133). This amount is nearly half the median monthly household expenditure in the baseline sample.

Participants were offered 29 different choice rounds, which are detailed in the Appendix. One of these choices would be implemented in reality, following a random draw made by the individual at the end of the experiment, and respondents knew this in advance. A subset of 15 of these rounds is the subject of the present paper. Analysis of other rounds will be the subject of future separate papers. $^{13}$

The first set of choices, rounds 1-4, asked individuals to decide on how to share an amount of money between "self” and "other," to be paid the day after, ${ }^{14}$ as a function of the return to giving (i.e. the added value to the amount given) and of the overall amount at stake. In this set of rounds, the rate of return to giving was either $0 \%$ or $200 \%$. ${ }^{15}$ The overall amount at stake for “self” was either 300 or 1,200 meticais. These rounds are referred to as “cash rounds” because respondents could only share resources with counterparts in the form of cash.

The second set of choices proposed to participants was the same as above, with an added option: individuals could decide whether gifts to the counterpart would be made in the form of a direct deposit to their counterpart's account on the next day (cash), or in the form of a delivery of goods (with the value that they choose to allocate) to their counterpart's doorstep (in-kind). Respondents were shown a catalog from which they could choose the goods they wanted to send.

\footnotetext{
${ }^{13}$ The other rounds not analyzed in the current paper are aimed at examining present-bias in sharing decisions. These were four cash rounds where all payments were delayed 60 days, and another ten rounds measuring the time consistency of choices using the convex time budget method. See the Appendix for further details.

14 The value at stake would be deposited in the respondent's or the counterpart's bank account the next day.

${ }^{15}$ A rate of return of $0 \%$ meant that exactly the amount shared by the respondent was given to the counterpart, while a $200 \%$ rate of return meant that the amount shared by the respondent from the endowment was tripled by the experiment and then given to the counterpart.
} 
They were told that they would be given the option of shopping for these items with the project team or of having the team directly shop for these items. Either way, the team would deliver the goods directly to the counterpart's doorstep. These rounds are referred to as "in-kind rounds." Due to time constraints, we did not ask for each in-kind round what the exact goods to be purchased would be. The exact goods to be delivered in kind were only chosen if an in-kind round was selected for implementation at the end of the experiment (and that allocation had nonzero allocation to in-kind).

In a first subset of choices (rounds 5-8), respondents were told that they would select the inkind goods if one of those rounds was chosen for implementation. These are the "in kind with respondent purchase” rounds. In a second subset of choices (rounds 9-12), the in-kind goods selection would be made by the counterpart ("in kind with counterpart purchase"). (See section 5 below for further discussion and analysis of rounds 9-12.)

In two additional rounds, the entire endowment of 1200 meticais was allocated to the counterpart, and the focus is on the respondent's preferences for making the allocation in cash vs. in-kind. In round 14, respondents were asked to divide the endowment into cash versus an inkind gift with respondent purchase. The choice in round 15 was similar, but in this case the options were cash vs. in-kind with counterpart purchase.

In practice, the experiment was implemented as follows. Each participant was given a number of tokens (which varied depending on each round, as detailed in the Appendix), and had two bins placed in front of him/her as in Appendix Figure 1. Depending on the decision round, he or she would be told that one bin represented a certain value for him or herself, whereas the other represented value for his or her counterpart in the MCCH. ${ }^{16}$ Whenever the participant needed to allocate value between cash or in kind, a smaller bin would be placed inside the counterpart's bin to represent the in-kind allocation. The order under which the different rounds were presented to the experiment participants was randomized as detailed in Appendix B. The actual round to be implemented was chosen randomly: the participant would pick a round from a closed box, as shown in Appendix Figure 4.

As noted in the introduction, we expect participants and their counterparts to meet again, and the anticipation of these repeated interactions should influence participants' choices. While our model is static, it can capture in reduced form certain repeated interactions that simply involve

\footnotetext{
${ }^{16}$ For each participant, the side on which each bin (representing "self” vs. "other”) was determined randomly.
} 
the donor's future consumption of the virtue good. However, the model does not capture a form of repeated interaction that involves the participant and counterpart playing, in effect, a trust game or trading favors outside of the experiment. In such interactions, the pair takes advantage of the high rate of return to giving that the experiment provides, and the counterpart returns part of the gift (or some other favor) to the participant after it is delivered. We note, however, that in kind gifts are much less divisible and fungible than money. This makes in kind gifts less attractive for purposes of trust game or favor trading interactions. The relative difficulty of returning gifts in kind, or recovering favors of equal monetary value, suggests that any such interactions should dampen the effects of motives for giving in kind.

\section{Empirical Results}

Most empirical analyses of the paper contain multiple observations per respondent; each respondent was asked to make choices in multiple versions of the dictator game and our interest is in comparing sharing decisions across choices that vary in dimensions such as the availability of the in-kind option, the endowment size, and the rate of return to giving. Some other empirical analyses will be at the respondent level (one observation per respondent), for example when we examine the relationship between a respondent's propensity to share in the experimental allocations and his or her transfer activity in the baseline survey.

A key outcome in this investigation is the fraction of the endowment that a respondent chooses to share with his or her counterpart. Table 1 presents some summary statistics on fraction shared with the counterpart in various rounds, looking separately at the cash rounds (14), the in-kind rounds with respondent purchase (5-8), and the in-kind rounds with counterpart purchase (9-12). Respondents share substantial fractions of their endowments on average: in the cash rounds the fraction shared is 0.396 , while in the in-kind rounds the figure is 0.451 and 0.436 when the purchase decision is made, respectively, by respondents and counterparts.

Table 3 provides a round-by-round examination of this outcome variable. Panel A presents the fraction shared in the cash rounds (rounds 1-4), which ranges from 0.380 to 0.429 . Panel B presents the fraction shared in the in-kind rounds with respondent purchase (rounds 5-8), which ranges from 0.428 to 0.480 . Finally, Panel C displays the fraction shared in the in-kind rounds with counterpart purchase (rounds 9-12); these figures range from 0.406 to 0.452 . 
When the in-kind option is available, a substantial amount of the sharing is done in kind, on average. In the in-kind rounds with respondent purchase (Panel B), $42.6 \%$ of sharing is in kind (0.191 divided by 0.448), while in the in-kind rounds with counterpart purchase (Panel C), the corresponding figure is $39.0 \%$.

Does sharing in the experiment correspond with real world transfers?

It is important to ask whether decisions in the experiment have any statistical relationship with non-experimental transfer behavior reported in the baseline survey. If they do, this increases confidence that our results are relevant for decisions outside of experimental conditions. ${ }^{17} \mathrm{We}$ regress various types of transfer activity reported in the baseline survey (transfers made to counterparts and received from counterparts, separately for cash, in-kind, and total) on the fraction that respondents share in the experiment (the average across in rounds 1-8). The fraction shared variable has a median of 0.4 , a mean of 0.424 , and a standard deviation of 0.189 .

Results presented in Table 4 reveal a positive relationship between experimental and "realworld" sharing. The fraction shared in the experiment is positively and statistically significantly associated with both real-world transfers made by respondents to counterparts, in cash and in total (columns 1 and 3). The coefficient on real-world transfers in-kind (column 2) is also positive, but smaller in magnitude and is not statistically significantly different from zero. Transfers received by respondents from counterparts are also positively associated with respondent sharing in the experiment, and the coefficients in the regressions for cash and total transfers are statistically significantly different from zero at the 10\% level (columns 4 and 6). The association between sharing in the experiment and self-reported transfer behavior lends credence to the idea that patterns revealed in this experiment reflect real-world behavior.

\section{Impact on sharing of in-kind option and other economic determinants: main results}

We now turn to estimating the impact on sharing of the in-kind option and other economic determinants. To address this question, we focus on rounds 1-8 (the four cash rounds plus the four in-kind rounds with respondent purchase), so there are eight observations per respondent.

\footnotetext{
${ }^{17}$ Importantly, our experiment endows respondents with substantial real resources and then asks them to make sharing decisions. The amounts involved in our experiment make them, in fact, important real-world decisions. The minimum endowment of 300 meticais amounts to $4.7 \%$ of total transfers to the counterpart in the last 12 months; for the maximum endowment of 1200 meticais the corresponding percentage is $18.9 \%$.
} 
Our main regression equation is as follows:

$$
y_{i r}=\xi+\alpha K_{r}+\beta R_{r}+\gamma E_{r}+\lambda_{i}+\varepsilon_{i r},
$$

where $y_{i r}$ is the fraction of the endowment shared with the counterpart for respondent $i$ in experimental round $r . K_{r}$ is an indicator variable equal to 1 if a round allows sharing with counterparts in kind, and is 0 otherwise (if $K_{r}=0$, the round only allows sharing in cash). $R_{r}$ is an indicator variable equal to 1 if there is a high rate of return to giving (200\%) in that round, and is 0 otherwise (if $R_{r}=0$, rate of return to giving is $0 \%$ ). $E_{r}$ is an indicator variable equal to 1 if the round involves a large endowment (1200 meticais), and is 0 otherwise (if $E_{r}=0$, the endowment is 300 meticais). $\lambda_{i}$ is a respondent fixed effect, and $\varepsilon_{i r}$ is a mean-zero error term.

The regression equation is estimated via ordinary least squares with standard errors clustered at the respondent level. The variation in $K_{r}, R_{r}$, and $E_{r}$ across rounds is imposed by the experiment and therefore exogenous. Coefficient estimates on these variables can therefore be interpreted as causal.

Results are in Table 5. We first exclude respondent fixed effects and in column 1 simply regress the fraction of the endowment shared with the counterpart on indicator variables for the in-kind rounds, rounds with the high rate of return to giving (200\% instead of $0 \%$ ), and rounds with a large endowment (1200 instead of 300 meticais). The coefficient on the in-kind indicator is positive and statistically significantly different from zero at the $1 \%$ level. Because each respondent makes decisions for each round, the coefficients are mechanically identical when individual fixed effects are included in the regression (column 2). Individual fixed effects explain a substantial fraction of variation in giving: the R-squared of the regression rises from 0.02 to 0.51 between columns 1 and 2 of the table. ${ }^{18}$ The "in-kind effect" - 5.5 percentage points - is large, amounting to about $14 \%$ of mean sharing across the cash rounds and 0.285 standard deviation of the fraction shared in the cash rounds.

Standard economic determinants also have statistically significant effects on sharing. In rounds with the high rate of return to giving, respondents share 2.4 percentage points more. The high endowment has the opposite effect, reducing fraction shared by 2.7 percentage points.

Strikingly, the in-kind effect is larger in magnitude than the impacts of these large changes in "standard" economic factors, the rate of return to giving and the endowment. P-values of linear

\footnotetext{
${ }^{18}$ Even though more residual variation is being explained with the addition of the respondent fixed effects, standard errors rise slightly owing to the reduction in degrees of freedom.
} 
hypothesis tests reported at the bottom of the table (in both columns 1 and 2) indicate that the coefficient on the in-kind indicator $(\alpha)$ is statistically significantly different from that of the high rate of return $(\beta)$, at the $5 \%$ level. The same is true for the test of the difference between the inkind coefficient and the coefficient on the high endowment indicator $(\gamma)$.

Figure 1 presents the cumulative distribution function of giving when transfers can be in cash alone (top line) and when either in-kind or cash giving is allowed (bottom line). The CDF for giving with the in-kind option is clearly shifted to the right, indicating that the in-kind option increases giving across the full giving distribution.

In column 3, we test whether the in-kind, rate of return, and endowment effects interact with one another by adding to the right-hand-side of equation (1) all possible interactions among the three indicator variables:

$$
y_{i r}=\xi+\alpha K_{r}+\beta R_{r}+\gamma E_{r}+\delta\left(K_{r} * R_{r}\right)+\phi\left(K_{r} * E_{r}\right)+\eta\left(E_{r} * R_{r}\right)+\lambda_{i}+\varepsilon_{i r},
$$

The in-kind effect is independent of the rate of return and the endowment size: neither interaction with the in-kind indicator is statistically significantly different from zero. The endowment size and the rate of return to giving do interact: the coefficient on that interaction term is negative and statistically significantly different from zero at the $5 \%$ level. P-values of hypothesis tests reported at the bottom of the table indicate that the rate of return effect is only statistically significantly different from zero when the endowment is low; and the endowment effect is only significantly different from zero when the rate of return to giving is high.

\section{Discussion and Additional Analyses}

In the context of the theoretical model presented above, the results presented so far indicate that respondents do value giving in kind, since in-kind sharing represents a substantial fraction of giving in rounds where it is allowed. In addition, we find that the in-kind option leads to increased sharing, a point on which the theory was ambiguous.

The analyses we present in this section are aimed at distinguishing among possible theories of these results.

Distinguishing among the paternalistic, public goods, and signaling models

We begin with an evaluation of the paternalistic, public goods, and signaling motivations behind in-kind giving. Our approach here is to test whether the "in-kind effect" changes when 
the choice of goods from the catalog for in-kind allocations are given to the counterpart (instead of the respondent).

In the rounds examined so far, where the respondents can ultimately choose exactly what the counterpart is getting (the "in-kind with respondent purchase" rounds), paternalistic, public goods, and signaling motivations could all help explain demand for in-kind giving. But when the ultimate choice of goods out of in-kind allocations is given to the counterpart (in the "in-kind with counterpart purchase” rounds), counterparts could choose freely from among private or public goods. As a result, if the public goods motive for giving were dominant then the demand for in-kind giving by respondents should be importantly diminished in these rounds. In addition, the "in-kind with counterpart purchase" rounds do not allow respondents to signal their knowledge of counterpart preferences, and so in-kind giving in those rounds could not be explained by the signaling model.

By contrast, if clients are motivated by paternalistic giving motives, they could still increase their giving in the "in-kind with counterpart purchase" rounds because that option makes it very difficult to use the gifted resources for socially undesirable expenses such as gambling, sex services, and possibly even alcohol. The “in-kind with counterpart purchase” rounds make vice good purchases less likely because choices in the in-kind rounds are made from the catalog presented at the outset of the experimental rounds, or by the requirement that the respondent accompany the project staff to purchase the goods in question. This set-up is likely to exclude socially undesirable purchases by counterparts, and - more to the point - is likely to discourage purchases of which counterparts know respondents would not approve.

For analysis of these “in-kind with counterpart purchase” rounds, we add four additional observations per respondent to the dataset analyzed in Table 5. These are rounds 9-12, where sharing is also allowed in-kind but if one of these rounds is chosen for implementation at the end of the experiment, the counterpart (rather than the respondent) makes the final purchase decision for any amounts allocated to in-kind by the respondent.

We estimate the following regression:

$$
y_{i r}=\xi+\alpha K_{r}+\beta R_{r}+\gamma E_{r}+\theta\left(K_{r} * C_{r}\right)+\lambda_{i}+\varepsilon_{i r},
$$

where $C_{r}$ is an indicator variable equal to 1 for the "in-kind with counterpart purchase" rounds (rounds 9-12), and 0 otherwise. The in-kind indicator variable $K_{r}$ is equal to 1 for all in-kind rounds (rounds 5-12). The coefficient $\theta$ on the interaction term $K_{r} * C_{r}$ is the difference in the 
effect of the in-kind option when counterparts make the final purchase decision, relative to the effect of the in-kind option when respondents make the final purchase decision. A large and statistically significant negative interaction term coefficient $(\theta)$ would be evidence in favor of the signaling or public goods models, as would an inability to reject the hypothesis that the in-kind effect is zero when counterparts make the final purchase decision $(\alpha+\theta=0)$.

Results are in Table 6. The empirical evidence favors the paternalistic model, rather than the public goods or signaling models of giving. While the coefficient on the interaction term coefficient $\theta$ is negative, it is small in magnitude (only about three-tenths the size of the "in-kind with respondent purchase” coefficient $\alpha$ ) and is not statistically significantly different from zero. $^{19}$

In the context of our theoretical model, these results indicate that the "in-kind with counterpart choice” rounds still give sufficient assurance to respondents that counterparts will use gifted resources in ways of which they approve, leading them to be about as willing to share with counterparts in those rounds as they are in the "in-kind with respondent choice" rounds. Because the "in-kind with counterpart choice” rounds offer respondents no ability to direct counterpart consumption to public goods or to signal their knowledge of counterpart preferences, we conclude that there is little evidence that either the public goods or signaling models could explain the "in-kind effect" in this experiment. ${ }^{20}$

Are respondents and counterparts playing a favor exchange game?

A possible alternative explanation for our results is that individuals are playing a favor exchange game, as in Abdulkadiroglu and Bagwell (forthcoming) or Hauser and Hopenhayn (2008). Respondents, aware that they are in a repeated relationship with their counterparts, may make transfers with the expectation of receiving a subsequent benefit. While existing favor exchange models do not provide a rationale for making gifts in kind, one might imagine that in-

\footnotetext{
${ }^{19}$ An F-test on the hypothesis that the in-kind effect is zero when counterparts make the purchase decision $(\alpha+\theta=\emptyset)$ is rejected at the $1 \%$ level (the p-value of the test, reported at the bottom of the table, is 0.001 ).

${ }^{20}$ These results are bolstered by a comparison of allocations to in-kind in rounds 14 and 15, wherein an endowment of 1200 meticais was mandated to be given entirely to the counterpart, and respondents were simply asked to split this money between cash and in-kind. In round 14 the respondent made the ultimate in-kind purchase decision, while in round 15 the counterpart did so. The amounts allocated by respondents to in-kind across these rounds are very similar and not statistically significantly different from one another (allocations to in-kind are 517 and 541 meticais in rounds 14 and 15, respectively).
} 
kind gifts are used as a system of accounting between parties to a transfer, being more tangible than cash and thus more likely to ensure later reciprocity.

We provide two pieces of evidence that respondents do not appear to be playing a favor exchange game with counterparts, and that a (modified) favor exchange model is unlikely to explain the in-kind effect we find. First, we analyze data from a post-experiment survey (conducted 30 days after the experiment) and find no evidence of favor exchanges: real-world net transfers from counterparts to respondents do not respond to our experimental transfers from respondents to counterparts. Second, we show that the in-kind effect is not larger for individuals who are more inclined to make in-kind gifts of durable (as opposed to more immediately consumable) goods; in other words, the in-kind effect does not seem to be motivated by a desire to provide a longer-lasting, tangible reminder of the gift. We provide details and further discussion of these analyses in Appendix C.

Are respondents simply valuing free delivery of in-kind goods?

Another hypothesis about the mechanism behind the in-kind effect is that respondents simply value the free delivery of the in-kind items, which was offered as part of the experiment. This explanation says that the increase in total sharing in the in-kind rounds simply reflects respondents "purchasing” the free delivery.

One way of testing this hypothesis would be to test whether the in-kind effect is larger for respondents whose counterparts live in another city, for whom delivery costs would be more important than when respondents and counterparts both live nearby. All our respondents live in Maputo City, while 21 percent of counterparts live outside of the city and its suburbs.

We test the "free delivery" hypothesis by running the following regression:

$$
y_{i r}=\xi+\alpha K_{r}+\beta R_{r}+\gamma E_{r}+\theta\left(K_{r} * F r_{r}\right)+\lambda_{i}+\varepsilon_{i r},
$$

where $\mathrm{Far}_{r}$ is an indicator variable equal to 1 if the counterpart lives outside Maputo City, and 0 otherwise. If the "free delivery" hypothesis were true, it should be the case that $\theta>0$.

Results are in Table 7. We are missing information on counterpart location for 21 respondents, so we first confirm in column 1 that the original in-kind effect (from estimation of equation 1) still holds for this slightly smaller sample. Results are almost identical to those in the full sample. 
In column 2, we present results from estimation of equation (5). Contrary to the prediction of the free delivery hypothesis, the coefficient on $\theta$ is actually negative and not statistically significantly different from zero at conventional levels. There is no support in these results for the free delivery hypothesis. ${ }^{21}$

\section{Evidence from post-experimental qualitative responses}

Our last evidence on the relevance of static models of directed giving as explanations for the in-kind effect comes from qualitative responses on the part of respondents. After all experimental rounds had been completed, we asked respondents several questions related to their motivations for giving in-kind. We instructed respondents to think about their responses in rounds 5-8 (in kind with respondent purchase) in comparison to their responses in the cash rounds (1-4).

Mean responses to these binary responses are presented at the bottom of Table 1. We first asked respondents what effect the in-kind option had on their willingness to share their endowments with counterparts. We were interested in the extent to which this qualitative response accorded with our quantitative findings in the experiment. 70 percent of respondents reported having shared more when the in-kind option was available. ${ }^{22}$

We then asked respondents four other questions aimed at revealing mechanisms behind the in-kind effect. 59 percent of respondents agreed with the statement, "I like the in-kind option because it gives me more control over what my relative is purchasing" (which we take to be representative of directed giving hypothesis). Smaller percentages agreed with other statements representing alternative mechanisms: 33 percent agreed with the statement "I like the in-kind option because of the free delivery of the in-kind items," and 46 percent agreed that "I like the in-kind option because I can get my relative items he/she can't get in his/her local area.” Finally, when we asked respondents to directly choose between two options by asking whether they agreed with the statement "When it comes to the in-kind option, I prefer the control aspect over the free delivery aspect," 73 percent expressed agreement.

\footnotetext{
${ }^{21}$ These results also are inconsistent with the related hypothesis that respondents like the in-kind option because it allows them to purchase goods for their counterparts that the counterparts cannot obtain in their local areas. This hypothesis arises because Maputo City is the country's largest urban area with the largest variety of goods. This "availability of goods" hypothesis would also predict that the in-kind effect would be larger for respondents whose counterparts live outside Maputo City.

${ }^{22}$ Note the text of the question refers to sharing with "relatives" but it should have been clear to respondents that this encompassed sharing with counterparts who are not relatives.
} 
We interpret these qualitative responses as supportive of the hypothesis that directed giving preferences are an important source of in-kind giving in the experiment. It is useful, however, to further test this claim by asking whether these qualitative responses are correlated with respondents' actual behaviors in the experimental rounds.

To this end, we created a variable intended to capture each individual's in-kind effect. We define the "individual in-kind effect" as the mean fraction given to counterpart in in-kind rounds (5-8) minus the mean fraction given to counterpart in the cash rounds (1-4), separately for each individual. The mean (std. dev.) of the individual in-kind effect is 0.055 (0.138), and its distribution is presented in Figure 2. The individual in-kind effect is greater than zero for 60.7\% of observations.

We then regress the binary variables representing the answers to the qualitative questions just described on the individual in-kind effect variable. Results are in Table 8. A first test of the consistency of the qualitative self-reports is the result in column 1: the individual in-kind effect strongly positively predicts whether a respondent reports that the in-kind option made him/her share more with the counterpart.

If a desire for control underlies the in-kind effect found in this experiment (our directed giving hypothesis), then we should find that the individual in-kind effect is positively correlated with the answers to the questions in columns 2 and 5 of the table (liking in-kind due to control, and preferring control over free delivery). This is exactly what we find: the coefficients on the individual in-kind effect are positive and significantly different from zero at conventional levels.

If other mechanisms, such as a desire for free delivery and obtaining hard-to-obtain goods for counterparts, were important, we should also find a positive and significant relationship between the individual in-kind effect and the dependent variables in columns 3 and 4 of the table. As it turns out, however, the evidence here is much weaker. While the coefficients on the individual in-kind effect are positive in both columns, in neither case is the coefficient statistically significantly different from zero at conventional levels. ${ }^{23}$

All told, these results indicate that respondents were attracted to the in-kind option because it gave them more control over what counterparts would consume. By contrast, other reasons why

\footnotetext{
${ }^{23}$ That said, we cannot formally reject that the coefficients in columns 3 and 4 are equal in magnitude to those in columns 2 and 5.
} 
respondents may have valued the in-kind option get much weaker (if any) support in these qualitative responses.

\section{Evidence against the "two box" hypothesis}

Another interpretation of the "in-kind effect" is that it reflects a kind of experimenter demand. In the in-kind rounds, respondents were presented with two boxes in which to place their chips to be shared with counterparts. In the cash rounds, respondents were presented with just one box for their shared chips. (In all cases there was only one box for chips kept by the respondent.) A worry is that respondents may have felt some implicit demand to put at least some chips in each box they were presented with. The question is whether the "in-kind effect" we document derives simply from the fact that the in-kind rounds involved the addition of one more box to receive shared allocations.

If this alternative interpretation were true, the prediction would be that the in-kind effect should be driven by (or at least be larger for) individuals who have a tendency to split their sharing with the respondent into both cash and in-kind allocations (in the in-kind rounds). By contrast, if the in-kind effect is just as large for individuals who do not split their in-kind allocations, this “two box" hypothesis would have less credence. We test this hypothesis and find no evidence in support of the "two box" hypothesis. We provide details of the analysis and a discussion of the results in Appendix D.

\section{Conclusion}

We conducted a lab-in-the-field experiment among microfinance bank clients in urban Mozambique. Respondents made allocations in a dictator game where their counterpart was the closest person to them outside of their household, and so are intended to represent interhousehold transfers from respondents to counterparts. Our aims were to test the extent to which individuals seek to make gifts in kind (in the form of goods and services, instead of purely cash), and to measure the impact on total giving when respondents could share resources in kind as well as in cash. We find that in-kind giving is commonly chosen even when respondents have the option of giving purely in cash. What's more, the option to give in kind raises total giving (compared to giving that can only be in cash). We provide auxiliary results suggesting that these results are most consistent with a model where individuals seek to direct recipient expenditures 
away from "vice” goods (a paternalistic giving model), rather than alternative models (public goods or signaling models).

In many developing country contexts, inter-household transfers are prevalent and large in magnitude. It is therefore important to understand the economics underlying decisions over such transfers. Our experiment reveals that a previously underappreciated factor - a desire to direct or control how gift recipients use transferred resources - has large effects on giving. We also show that this "in-kind effect” is large in comparison to other economic determinants of giving, such as the rate of return to giving and the size of the endowment to be shared. These findings should inform future theoretical and empirical investigations of inter-household transfers.

These results also have potential implications for policy and the design of financial products. Mechanisms that allow individuals to control or circumscribe how gift recipients use transferred resources can have positive impacts on the total value of transferred resources. A context in which such mechanisms could be highly relevant is in transfers from migrants to counterparts in home areas. Remittances sent by migrants are a very large international financial flow to developing countries, amounting to more than three times foreign aid (Yang 2012). There is an emerging body of field evidence on whether migrants seek to monitor and control how recipients use remittances. Ashraf, Aycinena, Martinez, and Yang (2012) find in a randomized field experiment that savings in migrant-origin households in El Salvador rise when migrants (in the US) are given new financial products that facilitate monitoring of savings in remittance-recipient households. Torero and Viceisza (2011) conduct a lab-in-the-field experiment testing whether migrants share more with remittance recipients in the form of groceries than in cash. Chen (2013) finds evidence of non-cooperative behavior related to use of household resources in migrant households. Ambler (2012) conducts a lab-in-the-field experiment testing whether remittance recipients use resources differently when migrants can monitor use. Batista and Narciso (2012) find in a randomized field experiment that increased communication flows between migrants and their networks cause an increase in the value of remittance flows to members of those networks.

While not directly tested in our experiment, our results could be relevant for understanding charitable giving to anonymous recipients. One approach that non-profits use to solicit donations is to commit to channel gifts to specific purposes. Often, charitable donations are even solicited for the purchase of specific items. For example, Heifer International, an international charity, 
offers donors the opportunity to purchase specific farm animals that will be given to households in developing countries. A recent edition of the organization's magazine seeks donations for among other items - a sheep (\$120), chicks (\$20), a water buffalo (\$250), and a rabbit (\$60) (Heifer International 2012). A model of directed giving similar to ours could explain the prevalence of such charitable appeals. An important avenue for future research would be to conduct lab-in-the-field as well as randomized field experiments testing whether the option to donate in kind increases charitable giving relative to giving that can only be in cash.

\section{References}

Abdulkadiroglu, Atila and Kyle Bagwell (forthcoming), “Trust, Reciprocity, and Favors in Cooperative Relationships,” American Economic Journal: Macroeconomics.

Altonji, J., F. Hayashi and L. Kotlikoff, "Is the extended family altruistically linked? Direct tests using micro data," American Economic Review, 82, 1992, pp. 1177-1198.

Altonji, J., F. Hayashi and L. Kotlikoff, "Parental Altruism and Inter Vivos Transfers: Theory and Evidence,” Journal of Political Economy, 105 (6), 1997, pp. 1121-1166.

Ambler, Catherine, “Don’t Tell on Me: Experimental Evidence of Asymmetric Information in Transnational Households,” mimeo, University of Michigan, 2012.

Angelucci, M., G. De Giorgi, M. Rangel, and I. Rasul, "Family networks and school enrolment: Evidence from a randomized social experiment," Journal of Public Economics, 94 (34), 2010, pp. 197-221.

Arrondel, Luc and Andre Masson, "Altruism, exchange or indirect reciprocity: what do the data on family transfers show?" in S. Kolm \& J.M. Ythier, eds., Handbook on the Economics of Giving, Reciprocity and Altruism, Elsevier, Ed. 1, Vol. 2, No. 2, 2006.

Ashraf, Nava, Diego Aycinena, Claudia Martinez A., and Dean Yang, "Remittances and the Problem of Control: A Field Experiment Among Migrants from El Salvador,” working paper, University of Michigan, 2012.

Ashraf, N., "Spousal Control and Intra-Household Decision Making: An Experimental Study in the Philippines," American Economic Review, 99(4), 2009, 1245-77.

Attanasio, O., A. Barr, J. Cardenas, G. Genicot, and C. Meghir, "Risk Pooling, Risk Preferences, and Social Networks," American Economic Journal: Applied Economics, vol. 4(2), April 2012, pp. 134-67. 
Barr, A. and G. Genicot, "Risk Sharing, Commitment, and Information: An Experimental Analysis," Journal of the European Economic Association, 6(6), 2008, pp. 1151-1185.

Batista, C. and G. Narciso, "Migrant Remittances and Information Flows: Evidence from a Field Experiment,” working paper, Nova University of Lisbon, 2012.

Becker, G. S., “A Theory of Social Interactions,” Journal of Political Economy, 82(4), 1974, pp. 1063-1094.

Benabou, R. and J. Tirole, “Incentives and Prosocial Behavior,” American Economic Review, 96 (5), 2006, pp. 1652-1678.

Bernheim, B. Douglas, Robert J.Lemke, and John Karl Scholz, "Do estate and gift taxes affect the timing of private transfers?” Journal of Public Economics, 88 (12), December 2004, pp. 2617-2634.

Bruce, N., and M. Waldman, "Transfers in Kind: Why They Can Be Efficient and Nonpaternalistic," The American Economic Review, 81(5), 1991, pp. 1345-51.

Camerer, Colin F., "Gifts as economic signals and social symbols," American Journal of Sociology, 94 (Supplement), 1988, S180-S214.

Camerer, C. and E. Fehr, "Measuring Social Norms and Preferences Using Experimental Games: A Guide for Social Scientists,” Ch. 3 in J. Henrich, R. Boyd, and S. Bowles, eds., Foundations of Human Sociality: Economic Experiments And Ethnographic Evidence From Fifteen Small-scale Societies, Oxford: Oxford University Press, 2004.

Chen, Joyce, "Identifying Non-Cooperative Behavior Among Spouses: Child Outcomes in Migrant-Sending Households,” Journal of Development Economics, 100(1), 2013, pp. 1-18.

Cox, D., and E. Jimenez, "Social Security and Private Transfers in Developing Countries: The Case of Peru," The World Bank Economic Review, 6 (1), 1992, pp. 155-169.

Cox, D., B. Hansen and E. Jimenez, "How Responsive are Private Transfers to Income? Evidence from a Laissez-Faire Economy," Journal of Public Economics, 88 (9-10), 2004, pp. 2193-2219.

DellaVigna, S., J. List, and U. Malmendier, "Testing for Altruism and Social Pressure in Charitable Giving,” Quarterly Journal of Economics, 127 (1), 2012, pp. 1-56.

Hauser, Christine and Hugo Hopenhayn (2008), “Trading Favors: Optimal Exchange and Forgiveness,” Collegio Carlo Alberto working paper no. 88, December. 
Heifer International, “The Most Important Gift Catalog in the World,” World Ark: The Magazine of Heifer International, Holiday Issue, 2012.

Jalan, J., and M. Ravallion, “Are the Poor Less Well Insured? Evidence on Vulnerability to Income Risk in Rural China,” Journal of Development Economics, 58 (1), 1999, pp. 61-81.

Jensen, R. T., "Do private transfers 'displace' the benefits of public transfers? Evidence from South Africa," Journal of Public Economics, 88(1-2), 2004, pp. 89-112.

Kazianga, H., “Motives for household private transfers in Burkina Faso,” Journal of Development Economics, 79 (1), 2006, pp. 73-117.

Leider, S., M. Mobius, T. Rosenblat, and Q. Do, “Directed Altruism and Enforced Reciprocity in Social Networks,” Quarterly Journal of Economics, 124 (4), 2009, pp. 1815-1851.

Ligon, E., and L. Schechter, “Motives for Sharing in Social Networks,” Journal of Development Economics, 99, 2012, pp. 13-26.

Pollak, R., 1988. “Tied Transfers and Paternalistic Preferences”, American Economic Review, 83 (5), 1993, pp. 240-244.

Prendergast, C. and L. Stole, “The Non-monetary Nature of Gifts,” European Economic Review, 45, 2001, pp. 1793-1810.

Torero, M., and A. Viceisza, “To Remit or Not to Remit: That is the Question. A Remittance Field Experiment,” Working paper, IFPRI, 2011.

Townsend, R., “Risk and Insurance in Village India,” Econometrica, 62 (3), 1994, 539-591.

Udry, C., "Risk and Insurance in a Rural Credit Market: An Empirical Investigation in Northern Nigeria,” Review of Economic Studies, 61, 1994, pp. 495-526.

Waldfogel, J., “The Deadweight Loss of Christmas,” American Economic Review, 83 (5), 1993, pp. 1328-1336.

Waldfogel, J., Scroogenomics: Why You Shouldn't Buy Presents for the Holidays, Princeton University Press, 2009.

Yang, D., “Migrant Remittances,” Journal of Economic Perspectives, 25 (3), 2011, 129-152. 


\section{Figure 1: Cumulative Distribution Functions for Sharing in Cash vs. In-Kind Rounds}

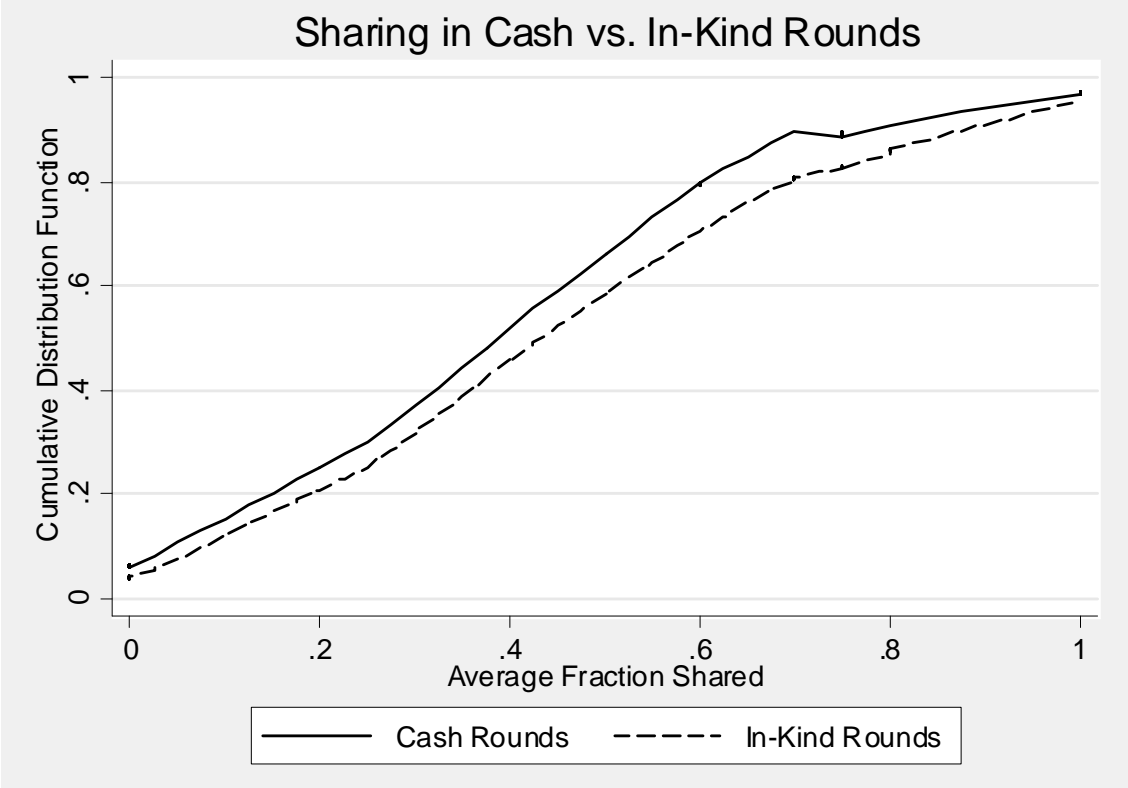

Note - Distributions shown are 1) solid line: average fraction shared in cash rounds (rounds 1-4); 2) dashed line: average fraction shared in in-kind rounds with respondent purchase (rounds 5-8).

\section{Figure 2: Distribution of Individual-level "In-Kind Effect"}

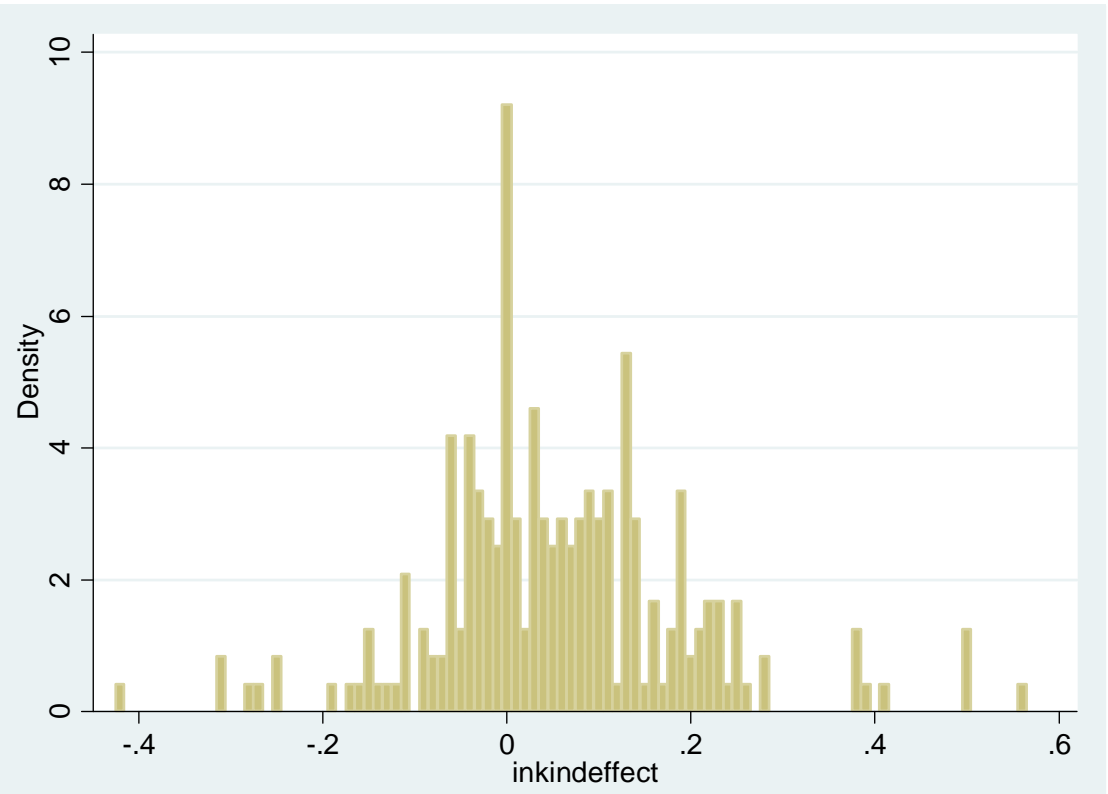

Note - N=239. Individual "in-kind effect" is mean fraction given to counterpart in in-kind rounds (rounds 5-8) minus mean fraction given to counterpart in cash rounds (rounds 1-4), calculated separately for each individual. Mean (std. dev.) of in-kind effect is 0.055 (0.138). Bin width $=0.01$. Highest frequency bin is $0(9.2 \%$ of observations). $60.7 \%$ of observations are in a positive bin. 


\section{Demographics}

Female (indic.)

Age in years

Born in Maputo City (indic.)

Ever married (indic.)

Household size

Highest education level completed: less than primary completion (indic.)

Highest education level completed: primary, no high school degree (indic.)

Highest education level completed: high school degree (indic.)

Highest education level completed: some post-high school (indic.)

Labor, expenditures, and assets

Currently employed (indic.)

Total household expenditure (monthly)

Has house (indic.)

Has land (indic.)

Has farm animals (indic.)

Has automobile (indic.)

Transfer characterstics

Counterpart lives outside Maputo City (indic.)

Cash transfer made to counterpart (indic.)

Amount of cash transfers to counterpart

In-kind transfer made to counterpart (indic.)

Value of in-kind transfers to counterpart

Cash or in-kind transfer made to counterpart (indic.)

Value of cash + in-kind transfers to counterpar

Cash transfer received from counterpart (indic.)

Amount of cash transfers from counterpart

In-kind transfer received from counterpart (indic.)

Value of in-kind transfers from counterpart

Cash or in-kind transfer received from counterpart (indic.)

Value of cash + in-kind transfers from counterpart

Fraction shared with counterpart in experiment

Cash rounds (rounds 1-4)

In-kind rounds with respondent purchase (rounds 5-8)

In-kind rounds with counterpart purchase (rounds 9-12)

Self-reported reasons for in-kind transfers

Having the in-kind option made me give more to my relative (indic.)

I like the in-kind option because it gives me more control over what my relative is purchasing (indic.)

I like the in-kind option because of the free delivery of the in-kind items (indic.)

I like the in-kind option because I can get my relative items that he/she can't get in his/her local area (indic.)

When it comes to the in-kind option, I prefer the control aspect over the free delivery aspect (indic.)
Mean Std. Dev.

Min. 10 th pct.

Median 90th pct.

Max. Num. Obs.

0.47

35.69

0.43

0.61

5.49

0.20

0.45

238

238

238
238

238

238

238

5,284

750

3,000

6,000

12,000

44,000

239

239

239

239

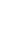

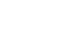

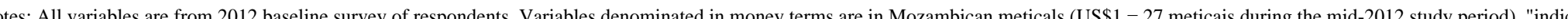
indicator variable. All transfer variables refer to last 12 months. 


\section{Table 2: Relationships of counterpart to respondent}

Count Share of total Cumulative share

\begin{tabular}{lrrr} 
Sibling & 77 & $32.4 \%$ & $32.4 \%$ \\
Friend & 41 & $17.2 \%$ & $49.6 \%$ \\
Cousin & 24 & $10.1 \%$ & $59.7 \%$ \\
Child & 23 & $9.7 \%$ & $69.3 \%$ \\
Parent & 20 & $8.4 \%$ & $77.7 \%$ \\
Nephew/Niece & 17 & $7.1 \%$ & $84.9 \%$ \\
Uncle/Aunt & 15 & $6.3 \%$ & $91.2 \%$ \\
Other relative & 10 & $4.2 \%$ & $95.4 \%$ \\
Spouse & 6 & $2.5 \%$ & $97.9 \%$ \\
Boyfriend/Girlfriend & 4 & $1.7 \%$ & $99.6 \%$ \\
Grandparent & 1 & $0.4 \%$ & $100.0 \%$ \\
\hline Total & 238 & $100.0 \%$ &
\end{tabular}

Note: Counterpart's relationship to respondent reported by respondent in baseline survey. Relationship not reported for one observation. 


\section{Table 3: Fraction of endowment shared with counterpart across rounds}

$\underline{\text { Panel A: }}$ Cash rounds

$\begin{array}{crrr}\underline{\text { Round }} & \text { Endowment } & \underline{\text { ROR }} & \text { Fraction shared, } \\ 1 & 300 & 0 \% & \underline{\text { total }} \\ 2 & 1,200 & 0 \% & 0.377 \\ 3 & 300 & 200 \% & 0.382 \\ 4 & 1,200 & 200 \% & 0.433 \\ & \text { Average fraction shared: } & 0.394 \\ & & \end{array}$

Panel B: In-kind rounds, respondent makes purchase

\begin{tabular}{|c|c|c|c|c|c|}
\hline & & & $\underline{\text { Fraction shared }}$ & Fraction shared & Fraction shared, \\
\hline Round & Endowment & $\underline{\mathrm{ROR}}$ & in cash & in kind & total \\
\hline 5 & 300 & $0 \%$ & 0.246 & 0.207 & 0.455 \\
\hline 6 & 1,200 & $0 \%$ & 0.244 & 0.188 & 0.433 \\
\hline 7 & 300 & $200 \%$ & 0.296 & 0.191 & 0.484 \\
\hline 8 & 1,200 & $200 \%$ & 0.251 & 0.183 & 0.433 \\
\hline \multicolumn{3}{|c|}{ Average fraction shared: } & 0.259 & 0.192 & 0.451 \\
\hline
\end{tabular}

Panel C: In-kind rounds, counterpart makes purchase

\begin{tabular}{|c|c|c|c|c|c|}
\hline & & & Fraction shared & Fraction shared & Fraction shared, \\
\hline$\underline{\text { Round }}$ & Endowment & $\underline{\mathrm{ROR}}$ & $\underline{\text { in cash }}$ & in kind & $\underline{\text { total }}$ \\
\hline 9 & 300 & $0 \%$ & 0.254 & 0.177 & 0.431 \\
\hline 10 & 1,200 & $0 \%$ & 0.237 & 0.172 & 0.409 \\
\hline 11 & 300 & $200 \%$ & 0.299 & 0.161 & 0.460 \\
\hline 12 & 1,200 & $200 \%$ & 0.277 & 0.167 & 0.444 \\
\hline \multicolumn{3}{|c|}{ Average fraction shared: } & 0.267 & 0.169 & 0.436 \\
\hline
\end{tabular}

Notes: Endowments are in Mozambican meticais (US\$1=27 meticais). "ROR" is rate of return to giving (each meticai shared with counterpart is multiplied by ROR and then shared). Figures based on full sample of 239 observations. In "cash" rounds, sharing with counterpart can only be in cash. In "in-kind" rounds, sharing with counterpart can be in any combination of cash or in kind. Prior to making choices in in-kind rounds, respondent is shown catalog with range of goods that can be purchased with amounts allocated to in-kind. Allocation of cash vs. in-kind sharing in rounds 5-12 is in money terms (e.g., x meticais shared in cash and y meticais shared in-kind). One round is chosen randomly to be implemented at end of experiment (including rounds described in Appendix that are not the focus of this paper.) Specific in-kind purchase decisions only made if an in-kind round is randomly selected for implementation at end of experiment. In "In-kind rounds, respondent makes purchase" (rounds 5-8), respondent makes actual purchase decision using resources allocated to in-kind if one of these rounds is chosen for implementation. In "In-kind rounds, counterpart makes purchase" (rounds 9-12), counterpart makes actual purchase decision using resources allocated to in-kind if one of these rounds is chosen for implementation. 


\section{Table 4: Correlation between experimental sharing and real-world transfers}

Ordinary least-squares estimates

Dependent variable:

Transfers made to counterpart...

in cash in kind in total

(1)

(2)

(3)

11946

$(5,904)^{* *}$

$(5,811)^{* *}$

(407)

769

522

1291

(2048)

$(186)^{* * *}$

239

0.02

239

0.00

R-squared

* significant at $10 \%$; ** significant at $5 \%$; *** significant at $1 \%$

Robust standard errors in parentheses.

Notes: Unit of observation is a respondent. "Fraction shared in experiment" is mean fraction of endowment shared with counterpart in rounds 1-8 (median 0.4, mean 0.424, std. dev. 0.189). See Appendix for exact round definitions. Dependent variables are from baseline survey, are denominated in meticais, and refer to last 12 months.
Transfers received from counterpart... in cash in kind in total

(4)

(5)

$\begin{array}{ccc}6788 & 132 & 6920 \\ (3,683)^{*} & (1072) & (3,892)^{*} \\ 117 & 1397 & 1514 \\ (1100) & (618)^{* *} & (1290)\end{array}$

239239

239

$0.02 \quad 0.00$ 


\section{Table 5: Determinants of fraction of endowment shared with relative}

Dependent variable: Fraction of endowment shared with counterpart Rounds: 1 through 8

(2)

(3)

\begin{tabular}{|c|c|c|c|}
\hline In-kind $(\alpha)$ & $\begin{array}{c}0.055 \\
(0.009)^{* * *}\end{array}$ & $\begin{array}{c}0.055 \\
(0.010)^{* * *}\end{array}$ & $\begin{array}{c}0.075 \\
(0.017)^{* *}\end{array}$ \\
\hline High rate of return to giving $(\beta)$ & $\begin{array}{c}0.024 \\
(0.012)^{* *}\end{array}$ & $\begin{array}{c}0.024 \\
(0.013)^{*}\end{array}$ & $\begin{array}{c}0.053 \\
(0.020)^{* *}\end{array}$ \\
\hline High endowment $(\gamma)$ & $\begin{array}{c}-0.027 \\
(0.009)^{* * *}\end{array}$ & $\begin{array}{c}-0.027 \\
(0.009)^{* * *}\end{array}$ & $\begin{array}{c}0.002 \\
(0.015)\end{array}$ \\
\hline In-kind $*$ High rate of return to giving $(\delta)$ & & & $\begin{array}{l}-0.020 \\
(0.018)\end{array}$ \\
\hline In-kind $*$ High endowment $(\phi)$ & & & $\begin{array}{l}-0.020 \\
(0.018)\end{array}$ \\
\hline High endowment $*$ High rate of return to giving $(\eta)$ & & & $\begin{array}{c}-0.037 \\
(0.018)^{*}\end{array}$ \\
\hline Constant & $\begin{array}{c}0.398 \\
(0.014)^{* * *}\end{array}$ & $\begin{array}{c}0.398 \\
(0.010)^{* * *}\end{array}$ & $\begin{array}{c}0.379 \\
(0.014)^{* *}\end{array}$ \\
\hline Respondent fixed effects & - & $\mathrm{Y}$ & $\mathrm{Y}$ \\
\hline Number of observations & 1912 & 1912 & 1912 \\
\hline R-squared & 0.02 & 0.51 & 0.51 \\
\hline \multicolumn{4}{|l|}{ Linear hypothesis tests (p-values): } \\
\hline$\alpha=\beta$ & 0.037 & 0.050 & 0.333 \\
\hline$\alpha=a b s(\gamma)$ & 0.033 & 0.046 & 0.000 \\
\hline$\beta=a b s(\gamma)$ & 0.876 & 0.884 & 0.070 \\
\hline$\alpha+\delta+\phi=0$ & n.a. & n.a. & 0.025 \\
\hline$\beta+\eta=0$ & n.a. & n.a. & 0.338 \\
\hline$\gamma+\eta=0$ & n.a. & n.a. & 0.026 \\
\hline
\end{tabular}

* significant at $10 \%$; ** significant at $5 \%$; *** significant at $1 \%$

Standard errors in parentheses, clustered by respondent.

Notes: Unit of observation is an allocation chosen by a respondent. 239 respondents included in each regression. There are 8 observations per respondent, corresponding to rounds 1 through 8 described in Appendix (2 rates of return X 2 endowments X allow or not allow in-kind gifts). "Inkind" is an indicator variable for the allocation allowing either in-kind or cash gifts to counterpart (omitted category: only cash gifts allowed). "High rate of return to giving" is an indicator variable for $200 \%$ rate of return to giving (omitted category: 0\% rate of return). "High endowment" is an indicator variable for the endowment equalling 1200 meticais (omitted category: endowment is 300 meticais). 
Table 6: Determinants of fraction of endowment shared with relative, including rounds with in-kind allocations where counterparts choose

Dependent variable: Fraction of endowment shared with counterpart

Rounds: 1 through 12

In-kind $(\alpha)$

$0.047 \quad 0.055$

$(0.009)^{* * *} \quad(0.009)^{* * *}$

High rate of return to giving $(\beta)$

$0.027 \quad 0.027$

$(0.012)^{* *} \quad(0.012)^{* *}$

High endowment $(\gamma)$

$-0.024 \quad-0.024$

$(0.008)^{* * *} \quad(0.008)^{* * *}$

In-kind, counterpart chooses exact gifts $(\theta)$

$-0.016$

$(0.010)$

Number of observations

2868

2868

R-squared

0.48

0.48

Linear hypothesis test (p-value):

$$
\alpha+\theta=0
$$

n.a.

0.001

* significant at $10 \%$; $* *$ significant at $5 \%$; $* * *$ significant at $1 \%$

Standard errors in parentheses, clustered by respondent.

Notes: Unit of observation is an allocation chosen by a respondent. 239 respondents included in each regression. Each regression includes respondent fixed effects. Compared to Table 3, this table adds 4 observations per respondent (rounds 9-12), in which respondent's counterpart makes the final decision on spending of resources allocated to "in-kind" (but where respondent still chooses amount in meticais allocated to in-kind "basket"). "In-kind, counterpart chooses" is indicator variable for these allocations (rounds 9-12). "In-kind" is indicator variable equal to one for both kinds of in-kind rounds (rounds 5 through 12). See Appendix for exact round definitions. See Table 3 for other variable definitions. 


\section{Table 7: Heterogeneity in impact of in-kind option, by location of counterpart}

Dependent variable: Fraction of endowment shared with counterpart

Rounds: 1 through 8

In-kind $(\alpha)$

$0.055 \quad 0.058$

High rate of return to giving $(\beta)$

$(0.010)^{* * *} \quad(0.011)^{* * *}$

$0.026 \quad 0.026$

$(0.014)^{*} \quad(0.014)^{*}$

High endowment $(\gamma)$

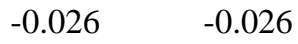

$(0.010)^{* * *} \quad(0.010)^{* * *}$

In-kind * Counterpart lives outside Maputo City $(\theta)$

$-0.016$

Number of observations

1744

1744

R-squared

0.50

0.50

Linear hypothesis test (p-value):

$$
\alpha+\theta=0 \quad \text { n.a. } \quad 0.072
$$

* significant at $10 \%$; ** significant at $5 \%$; *** significant at $1 \%$

Standard errors in parentheses, clustered by respondent.

Notes: Unit of observation is an allocation chosen by a respondent. 218 respondents included in each regression. Each regression includes respondent fixed effects. Rounds 1-8 included in sample. See Appendix for specific round definitions. "Counterpart lives outside Maputo City" is indicator variable for respondent's game counterpart living outside Maputo City. Sample size is smaller because of some missing data on counterpart location. See Appendix for exact round definitions. See Table 3 for other variable definitions. 


\section{Table 8: Correlation between individual in-kind effect and self-reported reasons for allocating in-kind}

\begin{tabular}{|c|c|c|c|c|c|}
\hline Dependent variable: & $\begin{array}{l}\text { Having the in- } \\
\text { kind option made } \\
\text { me give more to } \\
\text { my relative }\end{array}$ & $\begin{array}{l}\text { I like the in-kind } \\
\text { option because it } \\
\text { gives me more } \\
\text { control over } \\
\text { what my relative } \\
\text { is purchasing }\end{array}$ & $\begin{array}{l}\text { I like the in-kind } \\
\text { option because } \\
\text { of the free } \\
\text { delivery of the in- } \\
\text { kind items }\end{array}$ & $\begin{array}{l}\text { I like the in-kind } \\
\text { option because I } \\
\text { can get my } \\
\text { relative items } \\
\text { that he/she can't } \\
\text { get in his/her } \\
\text { local area }\end{array}$ & $\begin{array}{l}\text { When it comes to } \\
\text { the in-kind } \\
\text { option, I prefer } \\
\text { the control } \\
\text { aspect over the } \\
\text { free delivery } \\
\text { aspect }\end{array}$ \\
\hline & $(1)$ & $(2)$ & (3) & (4) & (5) \\
\hline Individual in-kind effect & $\begin{array}{c}0.621 \\
(0.207)^{* * *}\end{array}$ & $\begin{array}{c}0.392 \\
(0.232)^{*}\end{array}$ & $\begin{array}{c}0.252 \\
(0.230)\end{array}$ & $\begin{array}{c}0.365 \\
(0.225)\end{array}$ & $\begin{array}{c}0.438 \\
(0.207)^{* *}\end{array}$ \\
\hline Constant & $\begin{array}{c}0.665 \\
(0.033)^{* * *}\end{array}$ & $\begin{array}{c}0.564 \\
(0.035)^{* * *}\end{array}$ & $\begin{array}{c}0.312 \\
(0.033)^{* * *}\end{array}$ & $\begin{array}{c}0.444 \\
(0.035)^{* * *}\end{array}$ & $\begin{array}{c}0.704 \\
(0.032)^{* * *}\end{array}$ \\
\hline Number of observations & 239 & 239 & 239 & 239 & 239 \\
\hline R-squared & 0.03 & 0.01 & 0.01 & 0.01 & 0.02 \\
\hline \multicolumn{6}{|c|}{ * significant at $10 \%$; ${ }^{* *}$ significant at $5 \%$; *** significant at $1 \%$} \\
\hline \multicolumn{6}{|c|}{$\begin{array}{l}\text { Notes: Unit of observation is a respondent. "Individual in-kind effect" is mean fraction given to counterpart in in-kind } \\
\text { rounds (rounds 5-8) minus mean fraction given to counterpart in cash rounds (rounds } 1-4 \text { ), calculated separately for each } \\
\text { individual. See Appendix for exact round definitions. All dependent variables are indicators ( } 1 \text { if statement is true, } 0 \\
\text { otherwise), and are self-reported. }\end{array}$} \\
\hline
\end{tabular}


FOR ONLINE PUBLICATION

\section{APPENDIX FOR \\ Directed Giving: Evidence from an Inter-Household Transfer Experiment in Mozambique}

by

Catia Batista, Nova University of Lisbon and IZA

Dan Silverman, Arizona State University and NBER

Dean Yang, University of Michigan, NBER, and BREAD

\section{Appendix A: Supplementary material for Section 2 (Directed Giving in Theory)}

The public goods model of giving, in detail

We consider the problem of a donor deciding how much of a windfall to give to a recipient.

There are two goods, $x$ and $G$ with prices $p_{x}$ and $p_{G}$ denominated in meticais. The good $x$ is private. The good $G$ is public; its consumption is non-rival between the donor and the recipient. Different from standard models of public good provision, we will assume that, under normal circumstances, the donor cannot procure the public good himself. Only the recipient has control over the means of production for the public good. Thus, if the donor wants to influence public good production, his only means is to relax the recipient's budget constraint.

The public good, and the non-standard assumption about its production, allow several interpretations. The public good could be something like the health and welfare of shared children who live mostly with one parent (the recipient), or housing which is used primarily by the recipient and by the donor only on special occasions. In these cases, access to the technology that produces the public good is, in effect, controlled by the recipient. Alternatively, $G$ may be thought of as an investment good that will improve the earnings capacity or self-sufficiency of the recipient and thus reduce future needs to support the recipient (c.f. Bruce and Waldman, 1991). In this second interpretation, the donor values the public good because it amounts to an investment in teaching the recipient how to fish. Such investments typically require the active cooperation of the recipient in order to be productive.

If no gift is provided, a recipient with wealth $\omega$ chooses private good consumption $\left(x_{r}\right)$ and public good consumption $(G)$ to solve

$$
\begin{array}{ll} 
& \max _{x_{r}, G} u\left(x_{r}\right)+v(G) \\
\text { s.t. } & \omega-p_{x} x_{r}-p_{G} G \geq 0 \\
& x_{r}, G \geq 0 .
\end{array}
$$

Let $x_{r}^{*}(\omega), G^{*}(\omega)$ denote the optimal choices of a recipient with wealth $\omega$. Under standard assumptions the recipient's demand for the public good is well-behaved so if the donor were to give some amount of cash $c$ to the recipient the resulting public good production would simply be $G^{*}(\omega+c)$.

Now consider the donor's problem. We assume he faces the same prices as the recipient, but 
allow that his marginal utility from the two goods and his endowment $(\mu)$ may be different. By assumption, he cannot procure the public good directly. Therefore, the donor solves

$$
\begin{array}{ll} 
& \max _{x_{d}, c} U\left(x_{d}\right)+V\left(G^{*}(\omega+c)\right) \\
\text { s.t. } & \mu-p_{x} x_{d}-\frac{c}{1+r} \geq 0 \\
& x_{d}, c \geq 0,
\end{array}
$$

where $c$ is the cash gift to the recipient and, anticipating our experiments, $r$ is a relative price of giving $r$. When $r$ is higher, giving is cheaper.

Under standard assumptions, an interior solution to the donor's problem $\left(x_{d}^{*}, c^{*}\right)$ satisfies

$$
U^{\prime}\left(x_{d}^{*}\right)=p_{x}(1+r) V^{\prime}\left(G^{*}\right) \frac{\partial G^{*}}{\partial c^{*}}
$$

where, with some abuse of notation, $\frac{\partial G^{*}}{\partial c^{*}}$ denotes the marginal change in public good provision associated with an increase in the gift at the optimum. The donor's solution equates the marginal utility from another unit of his private consumption with the price-adjusted marginal utility of another unit of the public good, which can be produced only via cash gift to the recipient.

\section{Providing commitment ability}

How would the level of public good consumption and the market value of the gift change if, as in our experiment, the donor could commit the recipient to consume a minimum amount of the public good? Suppose that the donor can contribute directly to the public good, and assume (as usual) that this contribution cannot be sold by the recipient for cash. Let $g$ denote the donor's public good contribution and let $k$ denote its market value $\left(p_{G} g=k\right)$. In this case, the recipient solves

$$
\begin{array}{ll} 
& \max _{x_{r}, G} u\left(x_{r}\right)+v(G+g) \\
\text { s.t. } & \omega-p_{x} x_{r}-p_{G} G \geq 0 \\
& x_{r}, G \geq 0
\end{array}
$$

If the solution to $(\mathrm{P})$ is interior, then the recipient's optimal choices $\tilde{x}_{r}, \widetilde{G}$ satisfy $\frac{u^{\prime}\left(\tilde{x}_{r}\right)}{v^{\prime}(\widetilde{G}+g)}=\frac{p_{x}}{p_{G}}, \quad \tilde{x}_{r}=x_{r}^{*}(\omega+k)$ and $\widetilde{G}+g=G^{*}(\omega+k)$. In other words, the donor's demand that the recipient consume at least $g$ of the public good is not binding in this case; and the recipient's consumption does not depend on whether the gift with a market value of $k$ meticais was cash or an in-kind contribution to the public good.

In the more interesting case, the size of the donor's contribution, $g$, exceeds the amount of public good that the recipient would have chosen if the donation were made in cash. In this case:

Result 1. The donor strictly prefers an in-kind gift $g$ with market value $k$ to a cash gift of $k$. The donor prefers to give in-kind because it generates more consumption of the public good 
than would occur if he just gave cash. That is true because, in this simple model, the giver is not altruistic, and he values public good consumption monotonically.

Indeed, setting aside indifferences, in this model a donor would never offer a gift consisting of both cash and in-kind. A richer model of donor preferences that, instead of ignoring the recipient's utility only gave it a weight less than one, would predict that some gifts would combine both cash and in-kind. In these cases, the donor would equate the marginal utility from giving in-kind with the marginal altruistic utility from giving cash. We study this model in the next section below.

Result 2. The level of public good consumption is weakly higher when the donor has the ability to give in-kind and thus commit the recipient to a minimum level of public good consumption.

Proof: Let $G^{*}(i, g)$ denote the total level of public good consumption when a gift consisting of cash $i$ and public good $g$ is donated to the recipient. Let $\hat{c}$ denote the optimal gift when only cash can be given, and $\left(i^{\prime}, g^{\prime}\right)$ the optimal gift when both forms of giving are possible. If $\hat{c}=0$, the claim is trivially true. Suppose instead $\hat{c}>0$ and, contrary to the claim, $G^{*}\left(i^{\prime}, g^{\prime}\right)<G^{*}(\hat{c})$. The alternative allocation $\left(0, g^{\prime \prime}\right)$ where $g^{\prime \prime}=G^{*}(\hat{c})$ generates strictly higher utility from public good consumption than $\left(i^{\prime}, g^{\prime}\right)$. Most important, because the private good is normal, the recipient's marginal propensity to consume the public good is less than one and therefore

$$
p_{G} g^{\prime \prime} \leq \hat{c} .
$$

It follows that if the gift $\hat{c}$ was feasible then so is $\left(0, g^{\prime \prime}\right)$, and this alternative gift leaves the donor with at least as much own consumption as the strictly cash gift $\hat{c}$. By construction, marginal utility to the donor from public good consumption is the same at gift $\left(0, g^{\prime \prime}\right)$ as at $(\hat{c}, 0)$, and we have just argued that marginal utility from own consumption is weakly lower at $\left(0, g^{\prime \prime}\right)$. Thus, either $\left(0, g^{\prime \prime}\right)$ is optimal, or an even larger in-kind gift is preferred.

Inequality (1) isolates the key effect on the donor of providing him with the ability to commit the recipient to a minimum level of public good consumption. The possibility of such in-kind giving lowers the effective price, in terms of own consumption $x_{d}$, of producing the public good. This effective price change generates income and substitution effects which point in the same direction. The substitution effect gives incentive to buy more public good and less own consumption, and the income effect creates incentive to buy more of both.

If we understand the introduction of the commitment ability as reducing the price to the donor of generating public good consumption, it is straightforward to see that the net effect on the total market value of the gift, or its complement $p_{x} x_{d}$, is ambiguous. The lower effective price of producing the public good creates incentive for the donor to substitute out of own consumption and into giving (the substitution effect). But the lower effective price makes every level of public good production cheaper, in terms of $x_{d}$, to obtain, and thus creates incentive to purchase more own consumption (income effect). Whether the market value of the gift increases when the in-kind option becomes available depends, therefore, on the relative magnitude of these income and substitution effects.

Result 3. The introduction of the in-kind option has an ambiguous effect on the total market 
value of the gift.

\section{Extension to public goods model}

The basic model made the assumption that the donor's gifts were motivated only by his desire for public good production. Here we study a richer model with both public good production and altruism. In this model the donor places a positive weight on the utility of his recipient. The donor's problem is now

$$
\begin{array}{ll} 
& \max _{x_{d}, c, g}(1-\alpha)\left[U\left(x_{d}\right)+W\left(G^{*}(\omega+c, g)\right)\right]+\alpha u\left(x_{r}^{*}(\omega+c, g)\right) \\
\text { s.t. } & \mu-p_{x} x_{d}-\left(\frac{c+p_{G} g}{1+r}\right) \geq 0 \\
& x_{d}, c, g \geq 0
\end{array}
$$

where $\alpha \in[0,1)$ is the donor's weight on recipient's utility, and $x_{r}^{*}(\omega+c, g)$ is optimal private consumption choice of a recipient with wealth $\omega$ if she receives a gift consisting of cash $c$ and public good $g$, and

$$
W\left(G^{*}(\omega+c, g)\right)=V\left(G^{*}(\omega+c, g)\right)+\frac{\alpha}{1-\alpha} v\left(G^{*}(\omega+c, g)\right) .
$$

Under standard assumptions, an interior solution to the donor's problem satisfies

$$
\begin{aligned}
& U^{\prime}\left(x_{d}^{*}\right)=p_{x}(1+r)\left[(1-\alpha) W^{\prime}\left(G^{*}\right) \frac{\partial G^{*}}{\partial c^{*}}+\alpha u^{\prime}\left(x_{r}^{*}\right) \frac{\partial x_{r}^{*}}{\partial c^{*}}\right] \\
& =\frac{(1+r)}{p_{G}}\left[(1-\alpha) W^{\prime}\left(G^{*}\right)+\alpha u^{\prime}\left(x_{r}^{*}\right) \frac{\partial x_{r}^{*}}{\partial g^{*}}\right]
\end{aligned}
$$

The donor's solution equates the marginal utility from another unit of his private consumption both with the marginal utility of another meticais spent on a cash gift to the recipient (1), and with the marginal utility of another meticais spent on an in-kind gift to the recipient (2). In this case, the donor will optimally make both cash and in-kind gifts. 


\section{Appendix B: Description of Experimental Rounds}

The order of sections was randomized across respondents. Within each section containing more than one round, the order of the rounds was also randomized.

Section A (rounds 1-4)

Cash rounds: Giving must be in cash

\begin{tabular}{|c|c|c|c|c|c|c|}
\hline \multirow[b]{2}{*}{ Round } & \multirow{2}{*}{$\begin{array}{l}\text { Amount } \\
\text { (MZN) }\end{array}$} & \multirow{2}{*}{$\begin{array}{l}\text { Rate of } \\
\text { return } \\
\text { to } \\
\text { giving } \\
\text { (r) }\end{array}$} & \multicolumn{2}{|c|}{$\begin{array}{l}\text { Value per } \\
\text { chip }\end{array}$} & \multirow{2}{*}{$\begin{array}{l}\text { Total chips } \\
\text { in } \\
\text { endowment }\end{array}$} & \multirow{2}{*}{$\begin{array}{c}\text { Maximum } \\
\text { possible } \\
\text { payoff }\end{array}$} \\
\hline & & & $\begin{array}{l}\text { Bin } 1 \\
\text { Self }\end{array}$ & $\begin{array}{c}\text { Bin } \\
2- \\
\text { other }\end{array}$ & & \\
\hline 1 & 300 & $0 \%$ & 30 & 30 & 10 & 300 \\
\hline 2 & 1,200 & $0 \%$ & 30 & 30 & 40 & 1200 \\
\hline 3 & 300 & $200 \%$ & 30 & 90 & 10 & 900 \\
\hline 4 & 1,200 & $200 \%$ & 30 & 90 & 40 & 3600 \\
\hline
\end{tabular}

Section B (rounds 5-8)

In-kind rounds with respondent purchase: Giving can be in cash or in kind; respondent specifies in-kind allocation if round chosen for implementation

\begin{tabular}{|c|c|c|c|c|c|c|}
\hline Round & \multirow{2}{*}{$\begin{array}{c}\text { Amount } \\
\text { (MZN) }\end{array}$} & $\begin{array}{c}\text { Rate of } \\
\text { return } \\
\text { to } \\
\text { giving } \\
\text { (r) }\end{array}$ & $\begin{array}{c}\text { Value per chip } \\
\text { Self }\end{array}$ & $\begin{array}{c}\text { Bin 2 } \\
\text { Other } \\
\text { (divided: } \\
\text { cash / in- } \\
\text { kind) }\end{array}$ & $\begin{array}{c}\text { Total chips } \\
\text { in } \\
\text { endowment }\end{array}$ & $\begin{array}{c}\text { Maximum } \\
\text { possible } \\
\text { payoff }\end{array}$ \\
\hline 5 & 300 & $0 \%$ & 30 & 30 & 10 & 300 \\
\hline 6 & 1,200 & $0 \%$ & 30 & 30 & 40 & 1200 \\
\hline 7 & 300 & $200 \%$ & 30 & 90 & 10 & 900 \\
\hline 8 & 1,200 & $200 \%$ & 30 & 90 & 40 & 3600 \\
\hline
\end{tabular}

Section C (rounds 9-12)

In kind rounds with counterpart purchase: Giving can be in cash or in kind; counterpart specifies in-kind allocation if round chosen for implementation

\begin{tabular}{|c|c|c|c|c|c|c|}
\hline & & Rate of & \multicolumn{2}{|c|}{ Value per chip } & & \\
\cline { 4 - 5 } Round & $\begin{array}{c}\text { Amount } \\
\text { (MZN) }\end{array}$ & $\begin{array}{c}\text { return } \\
\text { to } \\
\text { giving } \\
\text { (r) }\end{array}$ & $\begin{array}{c}\text { Bin 1 } \\
\text { Self }\end{array}$ & $\begin{array}{c}\text { Bin 2 } \\
\text { Other } \\
\text { (divided: } \\
\text { cash / in- } \\
\text { kind) }\end{array}$ & $\begin{array}{c}\text { Total chips } \\
\text { in } \\
\text { endowment }\end{array}$ & $\begin{array}{c}\text { Maximum } \\
\text { possible } \\
\text { payoff }\end{array}$ \\
\hline 9 & 300 & $0 \%$ & 30 & 30 & 10 & 300 \\
\hline 10 & 1,200 & $0 \%$ & 30 & 30 & 40 & 1200 \\
\hline 11 & 300 & $200 \%$ & 30 & 90 & 10 & 900 \\
\hline
\end{tabular}




\begin{tabular}{|l|l|l|l|l|l|l|}
\hline 12 & 1,200 & $200 \%$ & 30 & 90 & 40 & 3600 \\
\hline
\end{tabular}

$\underline{\text { Section D (round 13) }}$

Respondent preferences over counterpart consumption categories, without cash.

\begin{tabular}{|c|c|c|c|c|}
\hline \multirow[b]{2}{*}{ Round } & \multirow[b]{2}{*}{$\begin{array}{l}\text { Amount } \\
(\mathrm{MZN})\end{array}$} & Value per chip & \multirow{2}{*}{$\begin{array}{l}\text { Total chips } \\
\text { in } \\
\text { endowment }\end{array}$} & \multirow{2}{*}{$\begin{array}{c}\text { Maximum } \\
\text { possible } \\
\text { payoff }\end{array}$} \\
\hline & & $\begin{array}{c}\text { Bin 2- Other } \\
\text { All in-kind }\end{array}$ & & \\
\hline 13 & 1,200 & 30 & 40 & 1,200 \\
\hline
\end{tabular}

Section E (round 14)

In-kind round with respondent purchase; entire endowment goes to counterpart. Respondent splits counterpart's chips into cash or in kind. Respondent specifies in-kind allocation if round chosen for implementation

\begin{tabular}{|c|c|c|c|c|c|c|}
\hline \multirow[b]{2}{*}{ Round } & \multirow[b]{2}{*}{$\begin{array}{c}\text { Amount } \\
(\mathrm{MZN})\end{array}$} & \multirow{2}{*}{$\begin{array}{l}\text { Rate of } \\
\text { return } \\
\text { to } \\
\text { giving } \\
\text { (r) }\end{array}$} & \multicolumn{2}{|c|}{ Value per chip } & \multirow[b]{2}{*}{$\begin{array}{l}\text { Total chips } \\
\text { in } \\
\text { endowment }\end{array}$} & \multirow[b]{2}{*}{$\begin{array}{c}\text { Maximum } \\
\text { possible } \\
\text { payoff }\end{array}$} \\
\hline & & & $\begin{array}{l}\text { Bin } 1 \\
\text { Other } \\
\text { (in } \\
\text { cash) }\end{array}$ & $\begin{array}{c}\text { Bin } 2 \\
\text { Other } \\
\text { (in-kind) }\end{array}$ & & \\
\hline 14 & 1200 & $0 \%$ & 30 & 30 & 40 & 1200 \\
\hline
\end{tabular}

Section F (round 15)

In-kind round with counterpart purchase; entire endowment goes to counterpart. Respondent splits counterpart's chips into cash or in kind. Counterpart specifies in-kind allocation if round chosen for implementation

\begin{tabular}{|c|c|c|c|c|c|c|}
\hline \multirow[b]{2}{*}{ Round } & \multirow[b]{2}{*}{$\begin{array}{c}\text { Amount } \\
(\mathrm{MZN})\end{array}$} & \multirow{2}{*}{$\begin{array}{l}\text { Rate of } \\
\text { return } \\
\text { to } \\
\text { giving } \\
\text { (r) }\end{array}$} & \multicolumn{2}{|c|}{ Value per chip } & \multirow[b]{2}{*}{$\begin{array}{l}\text { Total chips } \\
\text { in } \\
\text { endowment }\end{array}$} & \multirow[b]{2}{*}{$\begin{array}{c}\text { Maximum } \\
\text { possible } \\
\text { payoff }\end{array}$} \\
\hline & & & $\begin{array}{l}\text { Bin } 1 \\
\text { Other } \\
\text { (in } \\
\text { cash) }\end{array}$ & $\begin{array}{c}\text { Bin } 2 \\
\text { Other } \\
\text { (in-kind) }\end{array}$ & & \\
\hline 15 & 1200 & $0 \%$ & 30 & 30 & 40 & 1200 \\
\hline
\end{tabular}

In addition to the 15 rounds described above, respondents were also asked to make decisions in another 14 rounds that are not the subject of this paper but will be analyzed elsewhere. We briefly describe these other rounds here.

Section G, rounds 16-19: Four allocations analogous to rounds 1-4 (the cash rounds), but all payments were delayed by 60 days.

Section H, rounds 20-24: Five allocations where respondents were given endowments of 600 meticais, and had to decide how to allocate amounts for themselves between tomorrow at face value and 30 days away with a return. In each round, participants were presented with different rates of return on waiting for 30 days. These rates varied from 10 to $100 \%$.

Section I, rounds 25-29: Five allocations analogous to rounds 20-24 above, but where the allocations were between 60 and 90 days from the present. 


\section{Appendix C: Are respondents and counterparts playing a favor exchange game?}

In Section 5 of the main text, we addressed the possibility that a modified favor exchange model might explain the in-kind effect. In this Appendix we provide two pieces of empirical evidence that help rule out the relevance of a favor exchange model in this context. First, we find no evidence of favor exchanges related to our experimental transfers. Second, we find no evidence that the in-kind effect is motivated by respondents seeking to provide tangible reminders of their transfers to counterparts.

\section{No evidence of favor exchanges}

To test for favor exchanges in response to the experimental transfers, we use data from a follow-up survey we administered to respondents 30 days after the experiment. For cost and timing reasons we were only able to survey the first wave of respondents. We attempted to survey 125 respondents and had a success rate of $75.2 \%$ (94 respondents). ${ }^{1}$

The dependent variable of interest is net transfers from respondent to counterpart, which is transfers sent by the respondent to the counterpart minus transfers the counterpart sent to the respondent (in meticais) in 30 days following the experiment, as reported by the respondent in follow-up survey.

The independent variable of interest is the randomized component of payments to counterparts. The randomness arises because: 1 ) respondents chose to allocate different amounts (in meticais) to counterparts across experimental rounds, and 2) we randomly selected which round would actually lead to payouts to counterparts. To isolate this random variation, we must first control for average generosity of the respondent across rounds. We do so by controlling for expected transfer to counterpart in the regression, which is average value in meticais of transfer to counterpart across experimental rounds. Then, the variable of interest is the actual transfer to counterpart: the value (in meticais) of the transfer to the counterpart that was randomly selected to be paid.

When controlling for the expected transfer, the actual transfer is exogenous and therefore the coefficient on actual transfers can be taken as the causal impact of the exogenous part of the payment to counterparts on the dependent variable. (If we had failed to control for the expected transfer, the coefficient estimate on the actual transfer would not be exogenous, and we could not be confident that we had isolated a causal effect.)

If respondents and counterparts were engaged in favor exchange, we should see a negative coefficient on the actual transfer. Exogenously higher experimental transfers to counterparts should lead to lower subsequent net transfers from respondents to counterparts (higher subsequent transfers from counterparts to respondents, or lower subsequent transfers from respondents to counterparts, or both).

Regression results are in Appendix Table 2. In the first column, all variables in the regression are in levels (meticais). The coefficient on the actual transfer is not statistically significantly different from zero, and is in fact positive (the opposite of the prediction of a favor exchange model). In column 2 we check to see whether this result is sensitive to outliers by taking the

\footnotetext{
${ }^{1}$ Because this is a subset of our full sample, we first confirm that our main results persist in this subsample. Appendix Table 1 displays coefficient estimates analogous to those of columns 1 and 2 of Table 5, and confirms that coefficients on the in-kind indicator (and also those on the high rate of return and high endowment indicators) remain statistically significantly different from zero and are very similar in magnitude to those in the full sample.
} 
inverse hyperbolic sine transformation of both the dependent and independent variables (under which a variable $y$ becomes $\left.\log \left(y+\left(y^{2}+1\right)^{1 / 2}\right)\right)$, which can be interpreted in the same way as a logarithmic dependent variable, but does not suffer the same problem of being undefined at zero. ${ }^{2}$ The coefficient on the actual transfer is again not statistically significantly different from zero, and again positive (instead of negative) in sign.

We conclude from this analysis that respondents and counterparts do not appear to be engaged in a favor exchange game.

\section{No evidence of tangible reminder motivation for in kind gifts}

Another possible interpretation of the in-kind effect in this experiment is that in-kind transfers are tangible and durable reminders of the generosity or beneficence of the giver. Respondents may gain some benefit from such reminders to counterparts, since the tangibility of in-kind gifts may make them better than cash gifts at ensuring that the gift is reciprocated. This might make sense in the context of a favor exchange model (e.g., Abdulkadiroglu and Bagwell (forthcoming) or Hauser and Hopenhayn (2008)), modified so that in-kind gifts are more likely to be reciprocated than cash gifts.

If this hypothesis were true, we would expect the in-kind effect to be larger in magnitude for respondents who were inclined to make in-kind gifts of more durable items (rather than consumables), since the "tangible reminder" benefit would be more long-lasting for gifts of durable items. While the structure of the experiment is such that we did not ask (since it would have been too time-consuming for respondents) for a detailed itemization of all allocations to inkind, we did implement a different round intended to elicit more specific information on what kinds of in-kind items respondents would like to transfer to counterparts.

This quantitative information was collected from respondents in round 13 of the experiment. In this round, respondents allocated an endowment of 1200 meticais but were told that the entire amount had to be given to the counterpart in kind. Respondents were asked to specify the in-kind allocation in more detail across seven expenditure categories: housing, education, health, clothing, agricultural inputs, groceries, and other. ${ }^{3}$ Appendix Figures 1 and 2 show how this was implemented in practice.

Appendix Table 3 presents summary statistics of these choices. By far, housing is the category with the highest allocations, at a mean of 499 out of 1200 meticais. Education and groceries come in $2^{\text {nd }}$ and $3^{\text {rd }}$ place, with mean allocations of 197 and 170 meticais respectively.

To investigate the "tangible reminder" hypothesis, we created two definitions of consumables and durables out of these responses. In Definition 1, “consumables” are clothing, agricultural inputs, groceries, and other, while "durables" are housing, education, and health. In Definition 2, “consumables” are education, health, clothing, agricultural inputs, groceries, and other, while “durables” is housing alone.

We estimate a version of the regression equation that adds two interaction terms:

$$
y_{i r}=\xi+\alpha K_{r}+\beta R_{r}+\gamma E_{r}+\sigma\left(K_{r} * \text { Cons }_{r}\right)+\zeta\left(K_{r} * D u r_{r}\right)+\lambda_{i}+\varepsilon_{i r},
$$

\footnotetext{
${ }^{2}$ Burbidge, John B., Lonnie Magee, and A Leslie Robb (1988). “Alternative Transformations to Handle Extreme Values of the Dependent Variable,” Journal of the American Statistical Association, 83(401), 123-27.

${ }^{3}$ If this round was chosen for implementation, the respondent then would be asked for the specific items to be purchased within the categories to which funds were allocated. Choice of "other" required the respondent to specify in more detail. In all cases these were for small business expenses.
} 
where Cons $_{r}$ is the share of consumables in the respondent's allocation, and $D u r_{r}$ is the share of durables in the allocation in round 13. (Main effects of Cons $r$ and Dur $_{r}$ do not need to be included since they would be absorbed by respondent fixed effects.)

If the "tangible reminder" hypothesis were true, it should be the case that the in-kind effect is more positive for respondents for whom durables make up a higher share of in-kind sharing, compared to respondents for whom consumables make up a higher share of in-kind sharing. This would be a test that $\zeta>\sigma$ in equation (4).

Results are in Appendix Table 4, where we estimate equation (4) using the two different definitions of durables and consumables. In both regressions the conclusion is the same: we cannot reject equality of the coefficients on $\zeta$ and $\sigma$ on the interaction terms of interest (the pvalues of the F-tests of the difference in these two coefficients are far from conventional significance levels in both regressions).

Another way of viewing this result is to use the regression estimates to predict the in-kind effect for individuals who allocate all their in-kind giving to consumables, and to do the same for those allocating all their in-kind giving to durables. The "tangible reminder" hypothesis would predict that the in-kind effect should only appear, or be larger in magnitude, for the latter type of individual. The coefficient estimates are presented at the bottom of the table. The in-kind effect is very similar for both types of individuals (ranging from 0.047 to 0.062 across the columns). The coefficients for "all-consumables" and "all-durables" individuals cannot be statistically significantly distinguished from one another at conventional significance levels in either column of the table. In other words, the in-kind effect is just as large for individuals who allocate all their in-kind giving to consumables as it is for individuals who allocate their in-kind giving to durables.

We conclude from these analyses that there is little evidence that a version of a favor exchange model helps explain the in-kind effect. 


\section{Appendix D: Evidence against the "two box" hypothesis}

To test the "two box" hypothesis (described in Section 5 of the main text), we first create a variable (at the individual respondent level) that represents the respondent's propensity to split his or her sharing in the in-kind rounds into both cash and in-kind allocations. This variable, "propensity to split sharing in in-kind rounds," is the number of in-kind rounds where the respondent splits sharing between cash and in-kind, divided by the number of in-kind rounds that the respondent does any sharing at all. This variable will be interacted with the in-kind dummy in regressions analogous to those in Tables 6-8.

In such a regression it is also important to include another interaction term of "in-kind" with a variable representing the respondent's propensity to share at all in the in-kind rounds, because the action of splitting one's sharing is a subset of the action of sharing at all. We therefore create another variable, "propensity to share in in-kind rounds," which is the fraction of in-kind rounds (out of 4) with non-zero sharing. The interaction term with this variable will reveal the extent to which the "in-kind effect" is driven by individuals who have a propensity to share in the in-kind rounds. (This is not a particularly interesting question, but the interaction term must be included in the regression so we can correctly interpret the coefficient on "In-kind * Propensity to split sharing in in-kind rounds”.)

Appendix Table 5 presents regression results from estimation of the in-kind effect with these interaction terms. In the first column, we first show a regression with just the interaction term with "propensity to share in in-kind rounds." The coefficient on the interaction term is positive and statistically significantly different from zero at the 5\% level, indicating that the in-kind effect is driven by individuals who tend to share in the in-kind rounds.

In the second column, we add the interaction term with "propensity to split sharing in in-kind rounds.” This coefficient is small in magnitude and very far from achieving statistical significance at conventional levels. In this column the coefficient on the interaction term with "propensity to share in in-kind rounds" remains positive and significantly different from zero at the $10 \%$ level, indicating that the in-kind effect exists even for individuals who do not split their allocations at all in the in-kind rounds. These results indicate that the "in-kind effect" is in fact not being driven by individuals who tend to split their sharing in in-kind rounds between cash and in-kind, and so provides no evidence in support of the "two box" hypothesis. 


\section{Appendix Figure 1: Placement of bins during experiment}

(a) Cash rounds (1-4)

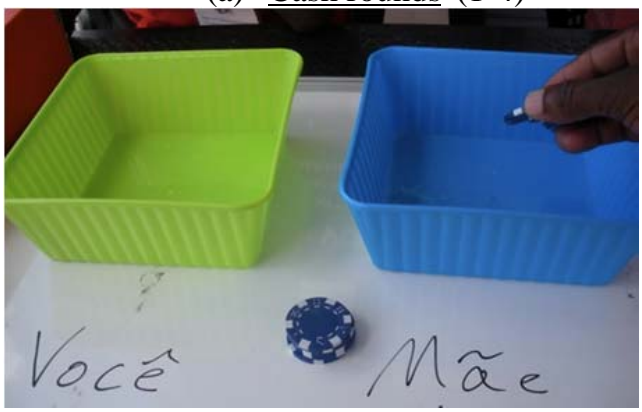

(b) In-kind rounds (5-12)

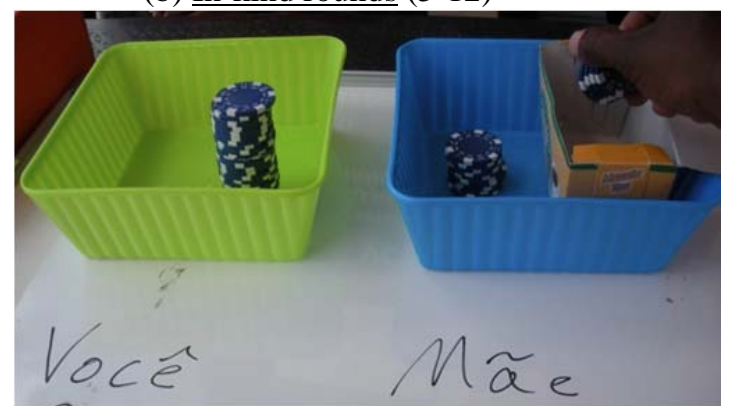

Respondents place chips in bins representing allocation to self and to counterpart. Placement of bins on left or right side randomized at the individual level. For in-kind rounds, an additional smaller box is included within counterpart's box, in which in-kind chips are to be placed.

\section{Appendix Figure 2: Choices presented for allocation of in-kind gifts}

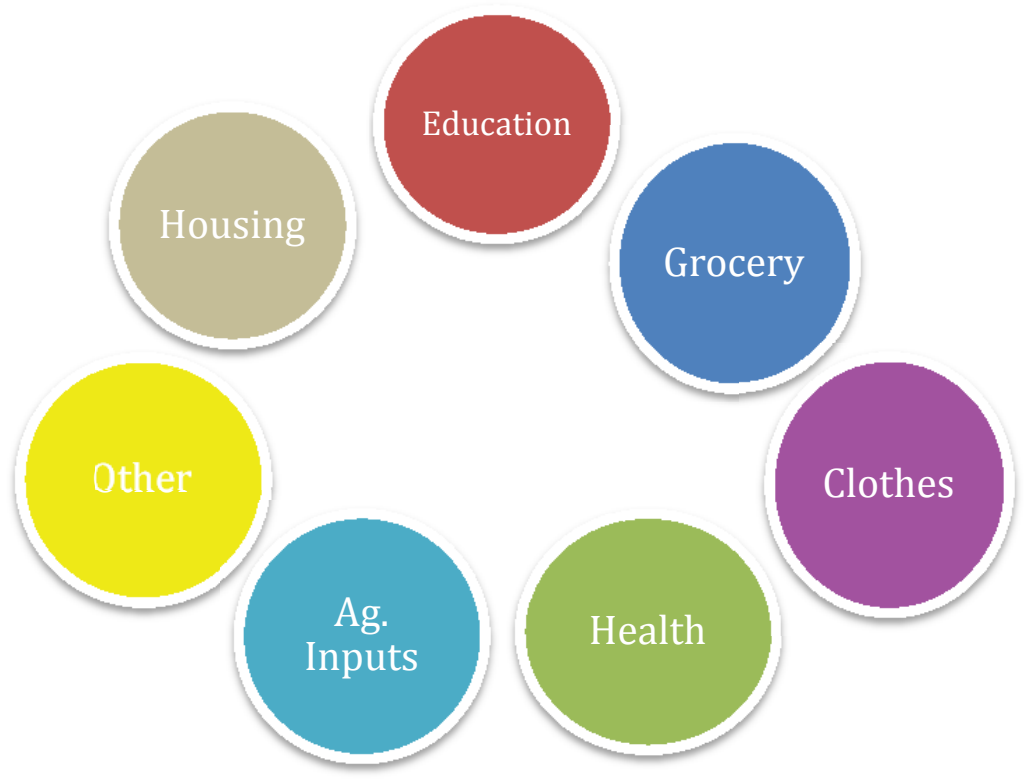

Visual presentation of in-kind categories across which to allocate 1200 meticais for counterpart in round 13 of experiment. 


\section{Appendix Figure 3: Placing tokens for allocation of in-kind gifts}

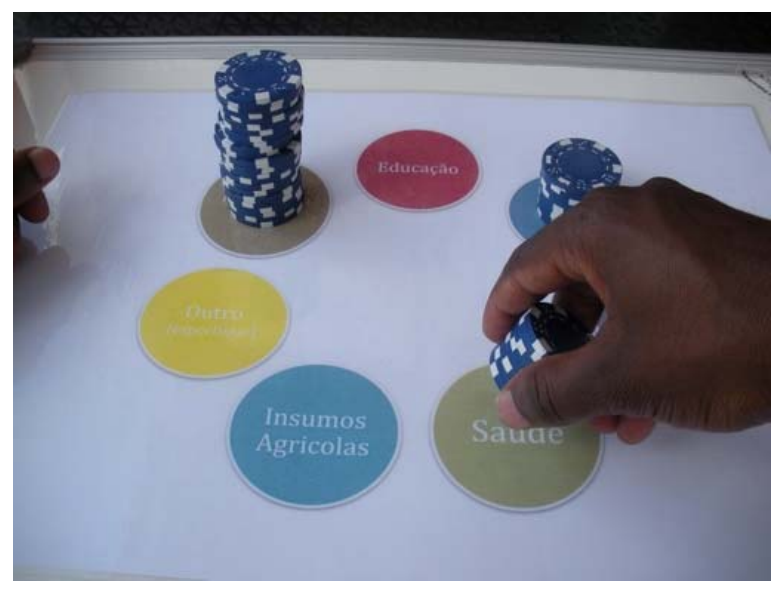

Respondent placing chips on different in-kind categories in round 13 of experiment.

\section{Appendix Figure 4: Final draw of transfer to be implemented}

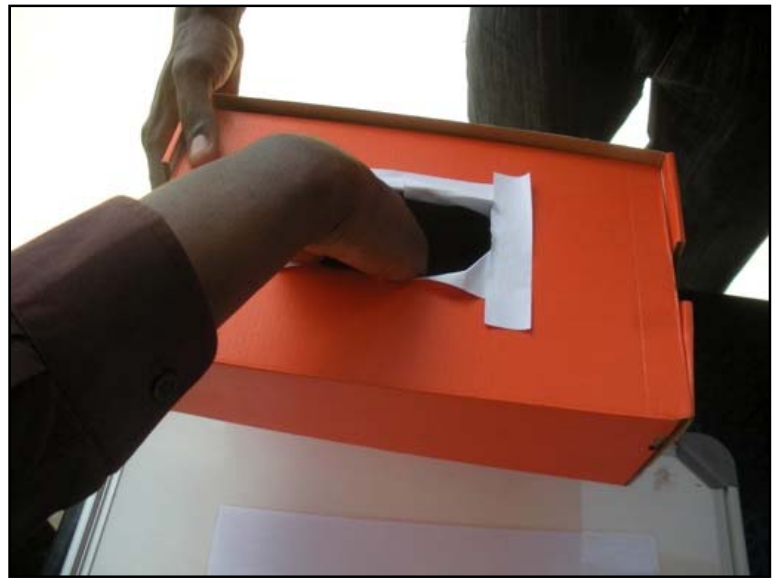

After conclusion of experimental rounds, respondent randomly selects a number from a closed box which determines which experimental round will be implemented in practice. 


\section{Appendix Table 1: In-kind effect in follow-up survey sample}

Dependent variable: Fraction of endowment shared with counterpart

Rounds: 1 through 8

(2)

$\begin{array}{lcc}\text { In-kind }(\alpha) & 0.063 & 0.063 \\ \text { High rate of return to giving }(\beta) & (0.015)^{* * *} & (0.016)^{* * *} \\ \text { High endowment }(\gamma) & 0.043 & 0.043 \\ & (0.023)^{* *} & (0.025)^{*} \\ \text { Constant } & -0.034 & -0.034 \\ & (0.013)^{* * *} & (0.014)^{* *} \\ & 0.379 & 0.379 \\ \text { Respondent fixed effects } & (0.019)^{* * *} & (0.015)^{* * *} \\ & & \\ \text { Number of observations } & - & \mathrm{Y} \\ \text { R-squared } & & \\ \end{array}$

* significant at $10 \%$; ** significant at $5 \%$; ** significant at $1 \%$

Standard errors in parentheses, clustered by respondent.

Notes: Unit of observation is an allocation chosen by a respondent. Sample restricted to 94 respondents completing the 30-day follow-up survey. Each regression includes respondent fixed effects. See Appendix for exact round definitions. See Tables 3 and 5 for variable definitions. 


\section{Appendix Table 2: Impact of random payment to counterpart on net transfers in next 30 days}

Dependent variable: Net transfers from respondent to counterpart

Specification of dependent and independent variables: Levels Inverse hyperbolic (meticais) sine transformation

$\begin{array}{lcc}\text { Actual transfer to counterpart } & 1.012 & 0.212 \\ & (1.088) & (0.298) \\ \text { Expected transfer to counterpart } & 1.665 & -0.745 \\ & (2.368) & (1.789) \\ \text { Number of observations } & & 94 \\ \text { R-squared } & 94 & 0.01\end{array}$

* significant at $10 \%$; ** significant at $5 \%$; *** significant at $1 \%$

Robust standard errors in parentheses.

Notes: Unit of observation is a respondent. Sample restricted to 94 respondents completing the 30-day follow-up survey. "Net transfers from respondent to counterpart" are transfers sent by respondent to counterpart minus transfers counterpart sent to respondent (in meticais) in 30 days following the experiment, reported by respondent in follow-up survey. "Expected transfer to counterpart" is average value in meticais of transfer to counterpart across experimental rounds. "Actual transfer to counterpart" is the value in meticais of the transfer to counterpart that was randomly selected to be paid the day following the experiment. Inverse hyperbolic sine transformation is $\log \left(y+\left(y^{2}+1\right)^{0.5}\right)$. 


\section{Appendix Table 3: Specific in-kind categories chosen by respondents (round 13)}

\begin{tabular}{|c|c|c|c|c|c|c|c|c|c|}
\hline Category & $\underline{\text { Share of total }}$ & $\underline{\text { Mean }}$ & $\underline{\text { Std. Dev. }}$ & $\underline{\text { Min. }}$ & $\underline{10 \text { th pct. }}$ & $\underline{\text { Median }}$ & 90th pct. & Max. & Num. Obs. \\
\hline Housing & $41.60 \%$ & 499.22 & 444.60 & 0 & 0 & 450 & 1,200 & 1,200 & 224 \\
\hline Education & $16.45 \%$ & 197.34 & 301.27 & 0 & 0 & 0 & 600 & 1,200 & 224 \\
\hline Groceries & $14.17 \%$ & 170.02 & 289.50 & 0 & 0 & 0 & 600 & 1,200 & 224 \\
\hline Health & $11.24 \%$ & 134.93 & 221.06 & 0 & 0 & 0 & 390 & 1,200 & 224 \\
\hline Clothing & $10.87 \%$ & 130.45 & 270.34 & 0 & 0 & 0 & 495 & 1,200 & 224 \\
\hline Agricultural inputs & $5.33 \%$ & 63.95 & 160.31 & 0 & 0 & 0 & 300 & 1,200 & 224 \\
\hline Other & $0.34 \%$ & 4.08 & 39.37 & 0 & 0 & 0 & 0 & 495 & 224 \\
\hline Total & $100.00 \%$ & $1,200.00$ & & & & & & & \\
\hline
\end{tabular}

Notes: Table reports respondent allocations to different in-kind expenditure categories in round 13 of experiment. Respondents are told that full endowment (1200 meticais) must be given to counterpart, and respondents must decide on how in-kind expenditures will be split across seven categories listed. If "other" chosen, respondents must specify in more detail (in all cases where "other" was chosen, respondents specified "small business expenses"). Prior to making choices in in-kind rounds, respondent is shown catalog with range of goods that can be purchased with amounts allocated to in-kind. Allocation of to different categories is in money terms (e.g., $\mathrm{x}$ meticais to housing, $\mathrm{y}$ meticais to education, etc.). If this round is chosen for implementation at end of experiment, respondent asked to specify exactly how amounts are to be spent within each chosen category (e.g., choosing specific construction materials for allocations within housing category). Some observations with data problems (allocations that do not add up to 1200 across categories) are dropped in this table. 


\section{Appendix Table 4: Heterogeneity in impact of in-kind option, by respondent preference for durables}

Dependent variable: Fraction of endowment shared with counterpart

Rounds: 1 through 8

In-kind $(\alpha)$

High rate of return to giving $(\beta)$

High endowment $(\gamma)$

In-kind * Respondent in-kind allocation to consumables (definition 1)

In-kind * Respondent in-kind allocation to durables (definition 1)

In-kind * Respondent in-kind allocation to consumables (definition 2)

In-kind * Respondent in-kind allocation to durables (definition 2)

Number of observations

R-squared

F-tests (p-values):

Joint significance of interaction term coefficients

Interaction term coefficients are different from one another

Predicted in-kind effect (std. err.) if respondent fully allocates in-kind to...

Consumables

Durables

$$
0.212 \quad 0.209
$$

$0.024 \quad 0.024$

$(0.013) * \quad(0.013)^{*}$

$-0.027-0.027$

$(0.009)^{* * *} \quad(0.009)^{* * *}$

$-0.157$

(0.199)

$-0.159$

(0.200)

$-0.163$

$1912 \quad 1912$

$0.51 \quad 0.51$

$0.728 \quad 0.624$

$0.940 \quad 0.539$

$\begin{array}{cc}0.055 & 0.047 \\ (0.026)^{* *} & (0.014)^{* * *} \\ 0.052 & 0.062 \\ (0.013)^{* * *} & (0.018)^{* * *}\end{array}$

* significant at $10 \%$; ** significant at $5 \%$; *** significant at $1 \%$

Standard errors in parentheses, clustered by respondent.

Notes: Unit of observation is an allocation chosen by a respondent. 239 respondents included in each regression. Each regression includes respondent fixed effects. Rounds 1-8 included in sample. See Appendix for exact round definitions. See Table 3 for other variable definitions. Interaction terms with "in-kind" are calculated from respondent choices in round 13, where respondent required to allocate full endowment (1200 meticais) to in-kind for counterpart, and is asked to specify in-kind allocation in more detail across 7 expenditure categories: housing, education, health, clothing, agricultural inputs, groceries, and other. Choice of "other" required respondent to specify, and in all cases these were for small business expenses. We created two definitions of consumables and durables out of these responses. Definition 1: "consumables" are clothing, agricultural inputs, groceries, and other; "durables" are housing, education, and health. Definition 2: "consumables" are education, health, clothing, agricultural inputs, groceries, and other; "durables" is housing alone. Interaction terms with "in-kind" are respondent allocations to these categories in round 13 as fraction of total endowment in that round (1200 meticais). 


\section{Appendix Table 5: Heterogeneity in impact of in-kind option, by tendency to split sharing into cash and in-kind}

Dependent variable: Fraction of endowment shared with counterpart

Rounds: 1 through 8

In-kind $(\alpha)$

$-0.071$

$-0.088$

(0.061)

High rate of return to giving $(\beta)$

0.024

0.025

$(0.013)^{*}$

(0.013)*

High endowment $(\gamma)$

$-0.027$

$-0.027$

In-kind * Propensity to share in in-kind rounds $(\theta)$

$(0.009)^{* * *}$

$(0.009)^{* * *}$

0.138

0.151

$(0.063)^{* *}$

$(0.078)^{*}$

In-kind * Propensity to split sharing in in-kind rounds $(\lambda)$

0.007

Number of observations

1912

1896

R-squared

0.51

0.50

Linear hypothesis tests (p-value):

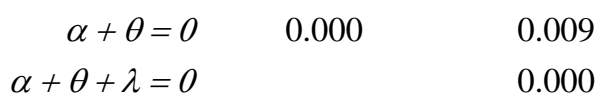

* significant at $10 \%$; ** significant at $5 \%$; *** significant at $1 \%$

Standard errors in parentheses, clustered by respondent.

Notes: Unit of observation is an allocation chosen by a respondent. 218 respondents included in each regression. Each regression includes respondent fixed effects. Rounds 1-8 included in sample. See Appendix for specific round definitions. "Propensity to share in in-kind rounds" is fraction of in-kind rounds (out of 4) with non-zero sharing, calculated at individual level. "Propensity to split sharing in in-kind rounds" is rounds where sharing is split between cash and in-kind, as share of total in-kind rounds with sharing, calculated at individual level. See Appendix for exact round definitions. See Table 3 for other variable definitions. 